\title{
The Effects of
}

\section{Government Licensing on E-commerce: \\ Evidence from Alibaba}

by Ginger Zhe Jin, ${ }^{1}$ Zhentong $\mathrm{Lu}_{1}{ }^{2}$ Xiaolu Zhou, ${ }^{3}$ Chunxiao Li ${ }^{4}$

\footnotetext{
${ }^{1}$ University of Maryland, College Park, and National Bureau of Economic Research

${ }^{2}$ Financial Stability Department Bank of Canada, Ottawa, Ontario, Canada K1A 0G9

${ }^{3}$ Xiamen University Xiamen, Fujian, China

${ }^{4}$ Alibaba Group

jin@econ.umd.edu, zlu@bankofcanada.ca, xiaoluzhou@xmu.edu.cn, Icx144022@alibaba-inc.com
}

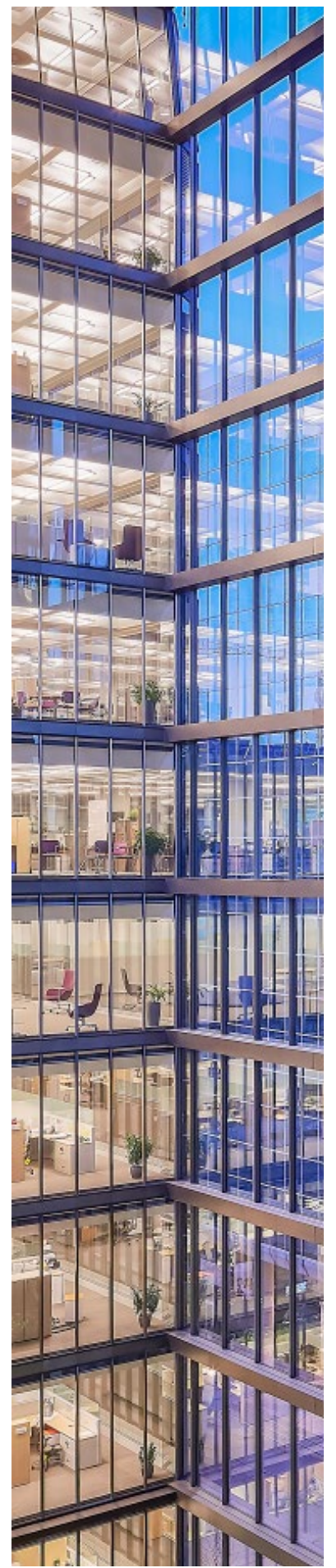

Bank of Canada staff working papers provide a forum for staff to publish work-in-progress research independently from the Bank's Governing Council. This research may support or challenge prevailing policy orthodoxy. Therefore, the views expressed in this paper are solely those of the authors and may differ from official Bank of Canada views. No responsibility for them should be attributed to the Bank 


\section{Acknowledgements}

We are grateful to Alibaba Group for providing us proprietary data, to Kaifu Zhang, Yuan Tian, and Zhe Yuan for helping us access the data, and to various Alibaba employees who patiently answered many of our questions. This research is supported by the National Natural Science Foundation of China (grant 71803162). Correspondence: Jin: University of Maryland, College Park \& NBER, jin@econ.umd.edu; Lu: Bank of Canada, zlu@bankofcanada.ca; Zhou: Xiamen University, xiaoluzhou@xmu.edu.cn; Li: Alibaba Group, Icx144022@alibaba-inc.com. Jin, Lu and Zhou were consultants for Alibaba Group during part of this research. The paper reflects the authors' opinions, not the opinions of Alibaba or any of the aforementioned institutions. All rights are reserved; all errors are ours. 


\section{Abstract}

Using proprietary data from Alibaba, we examine how the 2015 Food Safety Law (FSL) affects e-commerce in China. The FSL requires most food sellers on e-commerce platforms to obtain a valid online license for retail food handling. Because the FSL was rolled out progressively, we have a rare opportunity to observe a gradual transition from voluntary certification to partial licensing and mandatory licensing. Data summary shows that, conditional on sellers with valid licensing information, those that had a better online reputation and more online food sales before the FSL tend to display their FSL license earlier on the platform, and buyers are more willing to transact with a seller after she displays her FSL license. This positive response is stronger for younger and less reputable sellers, suggesting that the license provides useful information in addition to what consumers observe on the platform. To identify the causal impact of the FSL, we compare food and non-food categories via synthetic control matching. We find that the average quality of surviving food sellers has improved after partial and mandatory licensing, partly because those who are unwilling to obtain the FSL license must exit the platform. Despite an increase in seller concentration, the platform's gross merchandise value in the food category did not decline post FSL, nor did the average sales price increase significantly one year into the full enforcement of the FSL. This suggests that the FSL does not hamper the long-run performance of the regulated market, probably because it has enhanced seller quality and market transparency on the platform.

Topics: Market structure and pricing; Recent economic and financial developments

JEL codes: $D 82, K 23, L 5, L 8$ 


\section{Introduction}

The Internet enables transactions anytime, anywhere; but how to ensure product and service quality is a first order question for all online platforms. Indeed, online platforms have adopted many tools to address potential quality problems, including seller reputation $2^{2}$ voluntary certification, platform warranty, buyer insurance, third-party certification, and internal policing ${ }^{3}$ These tools are often imperfect, as some quality dimensions are not readily observable post transaction, many buyers do not leave a review, and some consumer reviews could be gamed or faked.

More generally, online platforms can set rules based on what they observe, but a lot of information crucial to consumer welfare - for example, the supply chain that contributes to product quality and seller qualification - is not always available to the platform, especially when the information is offline and sellers may not report it truthfully. Also, government can impose occupational licensing or quality standards and therefore obtain key information that is hidden from the platform. However, government is often short of resources and cannot monitor compliance in real time. In fact, it is difficult for a government intervention to take effect on a digital market until the platform tracks relevant data, detects potential violations, and enforces compliance. These pros and cons suggest that it is valuable to assess classical regulations in the new world of e-commerce.

In this paper, we evaluate a nationwide food safety regulation on Alibaba, China's largest e-commerce platform. China introduced the Food Safety Law (FSL) in 2015, requiring most food sellers on e-commerce platforms to obtain a valid, offline license for retail food handling. This licensing requirement is seller-specific but not product-specific. To be licensed, a food seller must have an offline production, packaging, and storage site that meets the local government's hygiene requirements. That site must have adequate facilities for disinfection and waste disposal, as well as adequate personnel for food safety and management. The cost

\footnotetext{
${ }^{2}$ See Bajari and Hortacsu (2004) and Tadelis (2016) for review of seller reputation on e-commerce platforms. In theory, when many buyers review the same product or the same seller, the average review should indicate the true quality of the product or the seller. However, this reputation system is imperfect, as buyer reviews may not be objective and independent (Dai et al. (2018)), sellers may have an incentive to fake or game reviews (Mayzlin et al. (2014), Luca and Zervas (2016)), and the platform's review policy could encourage retaliation between users (Dellarocas (2003)).

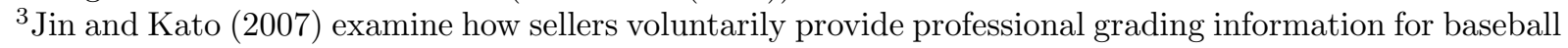
cards on eBay; Lewis (2011) studies how car photos help used car sales on eBay; Roberts (2011), Cai et al. (2014), and Hui et al. (2016) have studied buyer insurance and platform warrantees; Uber has used third-party companies (Checkr and Appriss) for driver background check on a continuous basis (news by Mashable.com, 7/13/2018); and almost all e-commerce platforms have an internal department that could warn, suspend and eliminate bad users. See Luca $(2017)$ and Tadelis (2016) for two recent reviews.
} 
of licensing can be non-trivial, especially for small, family-owned businesses in remote areas. To address this, China exempts sellers of raw agricultural products from the FSL. In the meantime, some special food types - for example, alcoholic drinks - were already subject to a separate licensing requirement before 2015. In light of this, we study how the 2015 FSL affects non-agricultural, non-alcoholic (NANA) food on Alibaba's two e-commerce markets (Taobao and Tmall). Because buyers see the two markets on the same digital interface, we treat them as a single platform.

The FSL was rolled out progressively. In January 2015, Alibaba notified all food sellers of the forthcoming Food Safety Law. It also updated its user interface so that licensed sellers could upload their local government license directly on the platform. In October 2015, Alibaba started to prohibit unlicensed food sellers from creating new listings on Taobao and Tmall, while existing listings remained valid. Starting in April 2016, Alibaba prohibited any unlicensed sellers from selling any food on its platform unless they are exempted by the FSL. Thus, starting January 2014, we observe periods of no regulation (January 2014-December 2014), voluntary certification (VC, January 2015-September 2015), partial licensing (PL, October 2015-March 2016), and mandatory licensing (ML, April 2016-June 2018). These changes are gradual rather than sudden regime shifts because some local governments are delayed in application approval and it is difficult to detect all violations immediately given the platform's size.

Unfortunately, due to a missing-data problem (described in Section 3), we observe the licensing status for only a subset of NANA food sellers and therefore cannot document the month-by-month licensing rate for the full sample. However, sales data is available for all NANA food sellers, so we can track a seller's sales revenue, average sales price, total quantity sold, average quality, and exit. Our main specification identifies the effect of the FSL via synthetic control matching between NANA food and non-food categories. This approach does not use any information on whether an individual NANA food seller has obtained an FSL license or not; therefore, it gets around the missing-data problem.

The data summary shows that, conditional on sellers with valid licensing information, those that had a better online reputation and more online food sales before FSL tend to display their FSL license earlier on the platform. This is not surprising, as larger and more reputable sellers may have a lower cost to meet the licensing requirement and expect more revenue loss if they have to exit the platform without a license. Moreover, within a seller, buyers are more willing to transact with the seller after she displays her FSL license. This positive response is stronger for younger and less reputable sellers, suggesting that the license 
provides useful information in addition to what consumers have observed on the platform.

After using synthetic control matching between NANA food and non-food categories, we find that the average quality of surviving sellers has improved after partial and mandatory licensing, partly because those who are unwilling to obtain the FSL license must exit the platform. Despite an increase in seller concentration, the platform's gross merchandise value (GMV) in NANA food did not decline post FSL, nor did the average sales price increase significantly one year after the full enforcement of the FSL. This suggests that the FSL does not hamper the long-run performance of the regulated market, probably because it has enhanced seller quality and market transparency on the platform.

Our work contributes to a large literature about occupational licensing and minimum quality standards. While the bulk of the literature focuses on offline licensing, we extend the study of licensing from local offline markets to a nationwide online market. To our best knowledge, only two recent papers study the role of offline licensing in online markets. Farronato et al. (2020) study sellers' voluntary reporting of having an offline license on an online platform for professional services. They find that consumers pay little attention to (validated) licensing information, but respond vigilantly to online customer reviews. Hall et al. (2019) study local licensing and background screening requirements of Uber drivers. They find that occupational licensing often does not improve ride safety or ride quality outcomes. In the meantime, costly licensing and screening requirements tend to discourage Uber drivers' entry into local ride-sharing markets. Unlike both studies, we find buyers respond positively and significantly to the FSL license information, and this response is stronger for young and less reputable sellers. Our findings suggest that licensing provides new and useful information in addition to the information already available on the platform.

More importantly, the gradual transition from voluntary certification (VC) to partial licensing (PL) and mandatory licensing (ML) allows us to dive deeper into the heterogeneous effects of certification and licensing. Theorists often view VC and ML as different tools to address the same information problem but believe VC is more flexible than ML because it allows sellers below the licensing standard to stay on the market (Leland (1979) and Shapiro (1986)). These low-quality sellers can serve consumers that prefer low-quality, low-price products. In contrast, ML is often advocated to eliminate poor-quality or unsafe products, but it could raise product price, limit entry, and reduce market competition. Corresponding to the ambiguous theoretical predictions $4^{4}$ empirical evidence on the effect of $\mathrm{VC}$ and ML

\footnotetext{
${ }^{4}$ Theoretical ambiguity could arise because of product differentiation. For example, ML eliminates belowstandard sellers, which mechanically improves the average quality available on the market (Leland (1979)). However, if competition is imperfect, it could motivate above-standard sellers to further improve quality,
} 
is often mixed 5 . We add to this rich literature by studying a gradual transition from no regulation to $\mathrm{VC}$ and $\mathrm{ML}$ in the same empirical setting. We do find the regulated category to have a higher Herfindahl index (HHI) post FSL, but the surviving sellers are of better quality and expand their listings. In sum, the total sales in NANA food did not decline significantly and the average sales price did not increase post FSL, relative to non-food categories. These findings suggest benefits from the FSL, despite higher market concentration and non-trivial costs in compliance and enforcement.

The rest of the paper is organized as follows. Section 2 describes the background. Section 3 presents the data, including data summaries that examine who has valid licensing information, who tends to display an FSL license earlier, who exits, and how consumers respond to FSL licensing as observed in the data. To identify the causal effects of FSL, Section 4 uses synthetic control matching to compare the NANA food category with non-food categories. The comparison is conducted at both the category level and the individual seller level. A brief conclusion is offered in Section 5 .

\section{Background}

In 2015, the Chinese government announced a new Food Safety Law (FSL), which for the first time requires online e-commerce food distribution to comply with the same regulations as the traditional, offline distribution channels.

The new law introduces a licensing system for food production and trade, setting standards for food production, storage, equipment, personnel, and raw materials. For example, it requires the ownership of an offline production or storage site that is clean and tidy and a prescribed distance away from pollution sources. It also requires the licensee to have pro-

because product differentiation softens price competition (Ronnen (1991)). This prediction is sensitive to the number of firms in the market (Scarpa (1998)), and in some cases the incentive to differentiate could even lower the average quality on the market (Garella and Petrakis (2008)). When ML is not fully enforced - as in our PL period-low-quality sellers may choose to stay below standard, while high-quality sellers are better motivated to comply with the minimum quality standard (Chen and Serfes (2012)).

${ }^{5}$ See Dranove and Jin (2010) for the literature of quality disclosure and certification. For ML, Law and Kim (2005) and Law and Marks (2009) find occupational licensing improved markets when it was hard to ascertain quality of professional services or quality of workers. In contrast, Pashigian $(1979)$ finds statespecific occupational licensing reduces the interstate mobility of professionals; Shepard (1978) finds higher prices of dental services and higher dentist income in jurisdictions that do not offer reciprocity in ML; Kleiner and Kudrle (2000) find no improved dental outcomes but higher prices of basic dental services in places with stricter licensing; Adams III et al. (2003) find fewer births by midwifery upon more stringent licensing; and Kleiner and Todd (2009) find mortgage broker licensing had no impact on the number of foreclosures but led to higher prices of mortgages. 
fessional equipment or facilities suitable for food production; have qualified equipment for disinfection, disposal and garbage; and have adequate personnel for food safety and management. Online platforms have the responsibility to display the license to consumers. Also, different types of food have different exposures to the licensing system. Non-agricultural products face the most stringent standard. Any sellers of non-agricultural products have to obtain a legal license. But raw agricultural products, for example, seafood that has not been hyper-processed, are exempted from mandatory licensing. Also, alcoholic drinks were already subject to a special licensing requirement before 2015, so the FSL does not apply to them.

Alibaba is the leading e-commerce provider in China. It owns two marketplaces, Taobao and Tmall, each of which has a non-trivial market share in China. The new law affects seven level-one food groups on Taobao and Tmall, including snacks, fruits/vegetables/seafood and cooked food, oil/rice/noodle/seasoning, nutrition food, tea, coffee/oatmeal, milk/infant formula. We thus focus on the effect of the FSL on non-agricultural non-alcoholic (NANA) food, and we pool all NANA food-related groups as one treatment category. All the other 134 level-one non-food groups form the control donor pool for the category-level analysis in Section 4 .

To implement the FSL licensing system, Alibaba took many actions from January 2015 to March 2016. Alibaba changed its user interface so that sellers can show their FSL licenses to consumers. Starting in January 2015, Alibaba notified all food producers and retailers, encouraging them to obtain a legal FSL license and disclose it online. Since October 2015, Alibaba has prohibited any new listings from unlicensed sellers. Alibaba also started to clean up the existing food listings from unlicensed sellers and finished it by the end of March 2016.

Because the FSL was implemented gradually on the market, we have a unique opportunity to compare the effect of voluntary certification and mandatory licensing in the marketplace. We have four periods with different intensities of regulation. From January 2014 (the beginning of our sample period) to December 2014, all sellers did not have a license, indicating a period with no regulation and no information disclosure. From January 2015 to September 2015, some sellers had obtained and disclosed their license, while, unlicensed sellers had also been allowed to sell online, suggesting a period of voluntary certification (VC). From October 2015 to March 2016, sellers had to disclose their licenses before listing new products, but sellers who listed products before the regulation were still able to sell without a license, corresponding to a period of partial licensing (PL). From April 2016 to June 2018 (the end of our sample period), all sellers needed a license to sell food products, indicating a period 
of mandatory licensing (ML).

The existing literature of $\mathrm{VC}$ and ML usually assumes perfect enforcement. In the context of the FSL, enforcement is rather difficult for at least two reasons. First, some sellers may game the system by uploading wrong documents or posting regulated items as nonregulated listings. It takes time and resources to validate documents and listings. Since the FSL applies nationwide but licensing criteria and paperwork vary significantly across local governments, it is impossible for the platform to detect all violations immediately and precisely. Throughout the whole rollout period, Alibaba worked closely with the government and received only one small fine for a minor violation in FSL enforcement. Second, the FSL put significant stress on local governments, which have to process a massive number of applications, send inspectors to inspect an applicant's physical facilities on site, and deal with all the idiosyncrasies of approval, appeal, reinspection, etc. We were told that lack of government resources had generated long delays between licensing application and licensing approval in some provinces. At times, the tension was so severe that Alibaba was allowed to acknowledge government receipt of licensing application as evidence of compliance and permit temporary selling without a final licensing approval. For these two reasons, our data most likely reflects a gradual transition from VC to ML, rather than sudden regime shifts.

\section{Data}

We have access to aggregated, proprietary data from Alibaba Group for all listings in all categories. From January 2014 to June 2018, the data includes product information, seller information, price, quantity sold, and revenue.

Product information includes the specific title of a listing, a set of product characteristics, and the product classification the listing belongs to (as defined by Alibaba). Excluding digital and service goods such as real estate, ticket booking and gift cards, Alibaba's classification has 141 level-one groups, 7 of which are food related.

Our data on food listings has a special indicator for alcoholic drinks, but it does not explicitly indicate whether a food item is agricultural or not. This presents a challenge, as only non-agricultural food is subject to the FSL law. To address it, we use listing titles to infer whether an item is agricultural or non-agricultural, depending on whether the item on sale comes in an original retail package from the manufacturer. We were told that this feature is a strong indicator for non-agricultural food, although not having it does not necessarily imply the item must be agricultural. For example, dried fruits that are individually wrapped 
by the manufacturer are non-agricultural for sure, but if a seller sells the same product by weight and without the original retail package, it is hard to tell whether it is agricultural or not. Whenever we have doubts, we classify the food listing as "unknown." In doing so, we identify $2 \%$ of food listings as agricultural food or alcoholic drinks, $32 \%$ as non-agricultural non-alcoholic (NANA food), and the rest, 66\%, as unknowns. Throughout the paper, we exclude all agricultural food, alcoholic drinks and the unknowns from the analysis. All results are robust if we include the unknowns ${ }^{6}$

We analyze data at both the category level and the individual seller level. Below we summarize the data at these two levels separately.

\subsection{Category-level data summary}

For category-level analysis, we take NANA food as one treated category and the 134 non-food level-one groups as control categories. Among non-food groups, seven focus on household items, including kitchen products, decorations, cleansers, gifts and festival products, household goods (lamp), and storage boxes. We refer to them as "household" categories. Because NANA food is most similar to household categories, part of our analysis will highlight the comparison between NANA food and household sellers.

Each category-month can be summarized by seller count, average sales price, average seller quality, and total GMV. By seller count, we mean the number of unique sellers that sold anything in category $c$ and month $t$. If a seller has sold in multiple categories in that month, she is counted as active in each of these categories. For each category-month, we can count the number of unique listings that have positive revenue. Across all listings in a category-month, we can sum up the total revenue and total units sold. The ratio of the two yields average sales price.

We rely on Alibaba's consumer rating system and return records to measure seller quality. Alibaba displays seller-specific rating scores in three dimensions: product description, service, and shipping. Each score is the average for all reviews given by previous consumers who have purchased from the seller in the last six months. Across the three scores, we compute an average for each seller. Thus, the resulting average score is seller-month specific, indicating the overall product, shipping, and service quality of the seller in the past six months. An average of the three average rating scores gives us one overall measure of average seller quality per category-month. Similarly, based on the return records, we compute "average

\footnotetext{
${ }^{6}$ Results are available upon request.
} 
percentage of returns due to quality problem per active seller" and "average percentage of returns due to counterfeit per active seller" as two other measures of average seller quality.

Seller reputation is another important attribute of sellers. At any particular time, Alibaba defines a seller's reputation as her total count of positive consumer feedback minus total count of negative feedback. By definition, this measure is cumulative across time and across all categories since the seller's entry onto the platform. Seller reputation is important for both buyers and sellers because it is highly visible on the platform and Alibaba uses it to classify sellers into stars and crowns. However, because it is cumulative and negative feedback is rare on average, seller reputation is more related to the seller's age and overall trading volume on the platform than to the seller's product or service quality per transaction. That said, being able to survive for a long period and for many transactions could in itself be interpreted as a signal of seller quality.

Across the four periods (no regulation, VC, PL, and ML), Table 1 summarizes our category-level sample for NANA food, the 7 household categories, and the other 127 non-food non-household categories. To avoid revealing Alibaba's business secrets, we normalize the summary statistics by deducting the platform-level mean and dividing the difference by the platform-level standard deviation in each month. The table thus shows the category-level variations relative to platform-wide average.

Panel A shows how the number of unique sellers varies over time for food and nonfood categories. In the no-regulation period, the number of food sellers was 0.112 standard deviation above the platform average, which further increased to 0.687 and 0.697 during VC and PL, but dropped below that of no-regulation (-0.021) after ML started. This suggests that many food sellers may have entered the market under VC but exited under ML. In contrast, the number of sellers increased steadily over time for household items and declined slightly for non-food non-household categories.

Panel B shows the category-level HHI in the four periods. For NANA food, HHI increased over time, especially after ML started. The HHI of household categories and non-food nonhousehold categories was relatively stable throughout the four periods.

Panel $\mathrm{C}$ indicates changes in average rating score per active seller. From no-regulation to VC, the average rating score declined for both NANA food and household categories, but the decrease was more pronounced in NANA food. From VC to PL and ML, the average rating score increased for NANA food and decreased for household categories. In comparison, the average rating score of sellers in non-food non-household categories went up and down by a much smaller magnitude. These patterns suggest that the average seller quality of NANA 
food may have improved as the FSL became more binding in PL and ML.

Panel D summarizes average reputation per active seller. For NANA food, average seller reputation was below platform average during no regulation, VC and PL but rose above platform average during ML. In comparison, average seller reputation was always above platform average in the household categories but declined steadily from no-regulation to ML. For non-food non-household categories, average seller reputation is close to the platform average, with a small gradual decline over time.

Panels $\mathrm{E}$ and $\mathrm{F}$ summarize average percentage of return due to quality problems or counterfeits per active seller. Both metrics were extraordinarily high for NANA food in the no-regulation period, but they decreased steadily throughout VC, PL and ML. In comparison, they either fluctuated or increased over time for non-food categories. Again, the patterns suggest that seller quality had a relative increase in NANA food as the FSL became more effective over time, consistent with what we have seen in average rating score and average seller reputation.

Panel G shows that average sales price (per unit sold) increased by a similar small amount for both NANA food and household categories, while it decreased slightly for non-food nonhousehold categories. As for category-level GMV, Panel H shows that GMV fluctuated for NANA food and non-food non-household categories but decreased in every period for the household categories.

\subsection{Seller-level data summary}

Category-level comparison helps to describe the big picture, but it ignores many heterogeneities within a category. As a supplement, we extract a random sample of individual sellers from NANA food and household categories.7 Below we first summarize the sample of individual NANA food sellers and then compare it to the sample of individual household sellers.

\subsubsection{The random sample of NANA food sellers}

We draw a random sample of 1,926 NANA food sellers from those that had NANA food sales for at least three months in 2014 (roughly 1\%). For the drawn sellers, we keep all

\footnotetext{
${ }^{7}$ As shown in Table 1 the household categories are more similar to NANA food than other control categories, in terms of average rating score and average sales price before FSL. Therefore, our random draw of individual sellers focuses on NANA food and household categories. But for category-level analysis, the number of household categories (seven) is too small, so we use all non-food categories to form the donor pool.
} 
their NANA food listings from January 2014 to June 2018 and aggregate the listings by seller-month. For each seller-month, we compute total revenue, total number of NANA food listings that have any sales, and average sales price (total revenue divided by total units sold).

By definition, such sampling is limited to incumbent sellers who had sales during the no-regulation period. Because new entrants have no pre-FSL period, they are not included in the individual seller sample. Towards the end of the paper, we will present statistics on the NANA food sellers that entered the platform post 2014.

Table 2 summarizes the 1,926 NANA food sellers in our random sample. A seller is defined as exiting the platform at month $t$ if $t$ is the last month she had positive NANA food sales and $t$ is not the last month of our data. By this definition, 1,613 (83.7\%) of the 1,926 sellers have exited by the end of our sample period. The high exit rate is not unique to NANA food, as the whole platform is characterized by high entries and exits, and sellers often jump categories over time. Over time, we observe a smaller number of exits in no-regulation and VC periods (292 and 387) than in PL and ML (419 and 828). The higher exit rate during PL and ML could be driven by tighter enforcement of FSL licensing in these two periods.

Although our sales data is complete for all sellers throughout January 2014 to June 2018, some historical FSL licensing data was overwritten in recent years. As a result, we have FSL licensing data for only a subset of NANA food sellers. Whenever we have FSL licensing data for a seller, we know exactly when she first obtained and displayed the FSL license on the platform 8 For those without FSL licensing data, we do not know whether they never displayed any FSL license before June 2018 or they had done so but the record is missing. Nevertheless, we were told that a seller that had any NANA food sales post the start of ML must have a valid FSL license or a reasonable excuse to be temporarily exempted from the delisting enforcement (e.g., local government had a technical delay processing the seller's FSL application).

Out of the 1,926 NANA food sellers in our random sample, we observe that $335(17.4 \%)$ display a FSL license by June 2018. As lack of license could be driven by missing data or by sellers not obtaining the FSL license, we zoom into the 901 sellers that had positive sales post ML. In theory, they should all have displayed the FSL license by the end of our data if the delay of local government approval is not too severe. Among them, 303 (33.7\% of

\footnotetext{
${ }^{8}$ This information is cumulative, as no sellers switched from being licensed to having no license unless they exited the NANA food category or the platform as a whole.
} 
901) displayed an FSL license sometime, while the other 598 did not. In contrast, only 32 (3.1\%) of the 1,296 sellers that did not sell any NANA food post ML have any FSL licensing data. This suggests that the vast majority of those exiting before ML did not bother to get licensed, while those that continued to sell post ML suffer a non-trivial missing-data problem.

Conditional on the sellers that had positive NANA food sales post ML, Table 3 compares them by whether their license data is missing. As shown in the first two columns, those with valid FSL licensing data were older, bigger and more reputable before FSL than the ones without FSL licensing data. However, post ML, those without FSL licensing data have a higher monthly GMV, although they are on average active for fewer months. To further examine the missing-data pattern, the last two columns of Table 3 zoom into the 382 sellers that sold any NANA food in 2018 (the last six months of our data). If local government delay is one important reason for missing licensing data, we should observe less missing in this subgroup. Indeed, only $35.2 \%$ (135 out of 382) of them miss licensing data, which is much lower than the percent missing data (66.3\%) among those that sold anything post ML. The two subgroups - with and without licensing data - are also more similar to each other once we condition on having sales in 2018. Above all, we conclude that data overwriting accounts for some of the missing data, but it is also possible that license approval was delayed in some local governments when ML started and such delay was alleviated over time. Since we are unable to tell the exact reason for each missing data point, our comparison between licensed and unlicensed sellers will likely underestimate the real difference, as the unlicensed group would include some that actually got the license.

Conditional on the 335 sellers with valid licensing information in our data, the second panel of Table 2 describes the distribution of the timing of their license display: only 96 of them $(28.7 \%)$ obtained and displayed their FSL license in the VC period, while 129 (38.5\%) got licensed in PL and the other 110 (32.8\%) in ML. This pattern suggests that the tighter enforcement in PL and ML may have given sellers an extra motivation to acquire and display an FSL license.

The next block of Table 2 summarizes GMV, number of orders, number of unique buyers, and total quantity sold per active seller-month. By active seller-month, we mean each seller that has positive sales in a specific month. In total, there are 41,272 active seller-months in our sample. To capture potential skewness, we show mean, median, and standard deviation for each measure. It is obvious that all these sales measures are highly skewed, with the mean and standard deviation much higher than the median. 
The last two blocks of Table 2 classify the 1,926 NANA food sellers by their reputation and age on the platform. Among all active seller-months, the average seller reputation is 21,932 , and the median is 2,419 . If we classify the 1,926 sellers by their average reputation in the no-regulation period, $669(34.7 \%)$ had a reputation no higher than 250 . We refer to them as "low-reputation" sellers and to the rest as "high-reputation" sellers.

Seller age is defined as the number of months since the seller opened her first store in Alibaba marketplaces. Across the whole sample of individual NANA food sellers, the average seller age (per active seller-month) is 21.89 months and the median is 10 . If we classify the 1,926 sellers by their average age in the no-regulation period, 641 of them $(33.3 \%)$ were less than 12 months old. We refer to them as "young" sellers and to the rest as "old" sellers.

\subsubsection{Who obtains an FSL license and who exits?}

Despite the missing-data problem, the observed licensing data may still tell us something about who got the FSL license and when. So we summarize it below.

Figure 1 plots the hazard rate of licensing for all NANA food sellers (before we sample individual sellers). Each point represents the fraction of sellers that started to display the FSL license during time $t$ if they had not been FSL licensed by the beginning of $t$. The three vertical lines indicate the start of VC, PL, and ML respectively. Because sellers without licensing data are counted as never licensed in this figure, the absolute hazard rate will underestimate the actual hazard rate, but relative change of hazard rate is still informative if the missing-data problem is random. Consistent with Table 2, Figure 1 1 shows that unlicensed sellers are more likely to obtain an FSL license right before PL and ML, probably because of the threat of more stringent enforcement from the platform. During ML, there is another spike of licensing hazard rate near the end of 2016, which may reflect batch approvals from some local governments at that time.

Accordingly, Figure 2 plots the exit hazard rate for NANA food sellers. Recall that exit is defined by a seller's last sales record in our data, which does not suffer any missing-data problem. Generally speaking, the exit hazard increased from no-regulation to VC, peaked during PL, and declined in ML. There was a small increase in the exit rate at the start of $\mathrm{VC}$ and PL, likely reflecting the (perceived) tightening in platform enforcement.

To further understand seller behavior, we apply a duration model with Cox proportional hazard to the sample of 1,926 individual NANA food sellers. In particular, we assume the hazard of seller $i$ uploading the FSL license at month $t$ is as follows, conditional on that she 
has not displayed such license by $t-1$ :

$$
\lambda\left(\text { discloselicense }_{t} \mid X_{i t}\right)=\lambda_{0}(t) \times \exp \left(X_{i t} \beta\right),
$$

where $X_{i t}$ includes the interactions between the dummies of VC, PL and ML periods and a seller's pre-FSL GMV and reputation (both in log). Because sellers cannot upload the FSL license until VC started in January 2015, the estimation sample excludes the no-regulation period, and the stand-alone terms of pre-FSL GMV and pre-FSL reputation are dropped (otherwise there would be perfect collinearity). By definition, every seller in our individual seller sample had positive sales in at least three months before FSL, so we compute her pre-FSL GMV and pre-FSL reputation as the monthly average during no-regulation.

Table 4 presents the results in two columns. The first column uses all of the 1,926 NANA food sellers in our random sample; the second column is conditional on the 335 sampled sellers that have some FSL licensing data. Obviously, the second column is a highly selected sample because sellers that intended to exit before ML may not bother to seek an FSL license. However, because we cannot distinguish them from those that got an FSL license but have missing values in our data, a focus on the licensed ones would at least tell us who tends to get the FSL license earlier than others. In comparison, the first column is subject to the missing-data problem and may underestimate the baseline hazard rate and the impact of observable factors.

As shown in Column 1 of Table 4, the hazard ratio of $\log$ (pre-FSL GMV) is significantly higher than one in VC and PL periods (1.356 and 1.180) but lower than one in ML (0.783). Results are qualitatively similar in Column 2 (but with smaller magnitudes), suggesting that sellers with higher sales before the FSL are more likely to obtain and upload an FSL license early rather than wait until the platform adopted the tightest enforcement in ML. This is not surprising, as sellers of higher pre-FSL sales should have more resources to pay for the licensing cost and would face more revenue loss if they have to exit the platform without a license. In comparison, the hazard ratio on $\log$ (pre-FSL reputation) follows a similar pattern: it is significantly higher than one in VC and PL (1.353 and 1.145) but not distinguishable from one in ML (1.011). Results are qualitatively similar in Column 2, suggesting that the pattern is unlikely driven by the missing-data problem.

We run a similar duration model for seller exit. For seller $i$, we code her as exiting in month $t$ if $t$ is the last month we observe her positive sales in NANA food and $t$ is not the last month of our data (June 2018). This definition may over-count exit if some sellers only sell seasonal NANA food that has high demand in May but little demand in June. 
Table 5 reports the duration results on seller exit. Although we could compute the hazard rate of exit during no-regulation, we choose to exclude the no-regulation period from the estimation sample because the sellers are sampled conditional on sales before FSL and our key variables - pre-FSL GMV and pre-FSL seller reputation-are computed from the seller's whole history during no-regulation. As we do not have any missing-data problem for sales and exit, we only report the results for the full sample of 1,926 NANA food sellers.

Consistent with the hazard of licensing, Table 5 shows that sellers of higher pre-FSL reputation are significantly less likely to exit in VC and PL periods. This makes sense, as more reputable sellers are more likely to obtain the FSL license during VC and PL and thus have less need to exit. In comparison, conditional on survival at the beginning of ML, they are more likely to exit during ML, probably because the platform has tightened FSL enforcement during ML and those that chose to be unlicensed have to exit. Surprisingly, those that had a higher pre-FSL GMV are more likely to exit during VC and PL, which is opposite to the effects of $\mathrm{VC}$ and $\mathrm{PL}$ on those that had a higher pre-FSL reputation. As pre-FSL GMV and pre-FSL reputation are positively correlated, we do not have a good explanation. One possibility is that FSL triggered multiple types of reactions: some were motivated to obtain the FSL license early and remain active post-FSL; others may try to clear out all food items before the FSL became binding. Both types could involve big or small sellers. In Section 4, we will use synthetic control matching for each individual seller to better understand how the FSL affects the distribution of NANA food sellers.

\subsubsection{Consumer response to FSL licensing}

Whether a seller is motivated to seek licensing depends on how consumers respond to the display of the FSL license. To gauge consumer response, we use the monthly records of the same 1,926 NANA sellers as in Tables 4 and 5. If we condition on active sellers (i.e., with positive sales in a month), the panel consists of 41,272 observations by seller-month. We refer to this sample as the active selling sample. If we include those who have not exited but made zero sales in a month, there are 56,364 seller-months. We refer to this sample as the potential selling sample.

Our econometric specification is:

$$
y_{i t}=\gamma_{1} 1_{\{\text {FSLlicense }, i t\}} \cdot 1_{\{V C\}}+\gamma_{2} 1_{\{\text {FSLlicense }, i t\}} \cdot 1_{\{P L\}}+\gamma_{3} 1_{\{\text {FSLlicense }, i t\}} \cdot 1_{\{M L\}}+\chi_{i}+\mu_{t}+\epsilon_{i t},
$$

where $i$ denotes the seller, $t$ is month, $\chi_{i}$ is seller fixed effects, and $\mu_{t}$ is year-month fixed 
effects. When we use the potential selling sample, the dependent variable $y_{i t}$ is the dummy of whether seller $i$ is making any NANA food sales in month $t$. Conditional on the active selling sample, the dependent variables are the seller's monthly GMV, number of orders, number of buyers, and quantities sold.

Our main independent variables are the interaction between the seller's license status $\left(1_{\{\text {FSLlicense,it }\}}\right)$ and the dummies of VC, PL and ML. Again, because no license is available until VC started, the stand-alone term of $1_{\{\text {FSLlicense,it }\}}$ is dropped due to collinearity. All regressions include seller fixed effects; thus $\left\{\gamma_{1}, \gamma_{2}, \gamma_{3}\right\}$ measure how $y_{i t}$ changes within the same seller after she displayed the FSL license on the platform. We do not include seller reputation, quality, or average sales price on the right-hand side because seller fixed effects already absorb each seller's pre-FSL characteristics, and any concurrent change in reputation, quality or price could reflect consumer response to FSL licensing. For this reason, $\left\{\gamma_{1}, \gamma_{2}, \gamma_{3}\right\}$ should not be interpreted as the causal effect of randomly assigning FSL license to an incumbent NANA seller. Rather, they capture the average within-seller change of sales likelihood and sales amount when the seller switches from no license to having an FSL license in a particular post-FSL period. Licensed sellers could be a selected group, and the licensing dummy reflects whatever factors drive the seller's licensing decision.

Table 6 shows the estimation results for the full sample of 1,926 NANA food sellers. According to Column (5), displaying an FSL license during the VC period is related to a $14.1 \%$ higher probability of making any sales, relative to the no-regulation period. The boosting effect of licensing in PL and ML is even higher at $31 \%$ and $32.3 \%$. Conditional on making sales, Column (1) shows that displaying an FSL license in VC is associated with $30.4 \%$ more GMV within the same seller, as compared to pre-FSL. Positive effects also occur in PL (53.8\%) and ML (69.7\%). Similar patterns appear in other sales measures. In short, consumers' positive response to FSL licensing is consistent with the fact that some sellers sought licensing even when the mandate was not fully in effect.

Tables 7 and 8 rerun the same specification by subsamples, according to whether a seller was more than 12 months old before FSL and whether a seller's pre-FSL reputation was over 250. Comparing young and old sellers in Table 7, we find that 13 out of all 15 coefficients are higher for young sellers. The same pattern occurs in Table 8, where all 15 coefficients are higher for low-reputation sellers than for high-reputation sellers (although the four coefficients on low-reputation sellers in $\mathrm{VC}$ are not significant from zero due to insufficient data variations). Some of the found effects may not be fully attributable to FSL licensing as we do not control the full information set of consumers. But the pattern 
suggests that FSL licensing helps consumers to trust younger and lower-reputation sellers on the platform, probably because the license provides useful information in addition to what consumers can observe on the platform.

The above results are based on the full sample of 1,926 NANA food sellers, which could be biased due to the missing-data problem in licensing records. To the extent that the unlicensed sellers in our data could have obtained an FSL license in reality, these results could underestimate the true effect of FSL license display. Because of this caveat, we regard these results as data description rather than the causal effects of FSL. Later on, we will identify the effect of FSL via synthetic control matching, which does not depend on any seller's licensing status.

\subsubsection{Comparing NANA food sellers with household sellers}

Table 9 compares the sample of 1,926 NANA food sellers to a random sample of 5,721 household sellers. These household sellers are random draws from those that were actively selling household items in at least three months pre-FSL. We compare these two types of sellers in their monthly average revenue, average rating score, average sales price, and number of active listings. To avoid revealing Alibaba's business secrets, all numbers are normalized by sample mean and sample standard deviation.

As shown in Panel A of Table 9, the average monthly revenue per active NANA food seller dropped from no-regulation to VC but increased in PL and ML, and its absolute level in PL and ML was higher than that of no-regulation. In comparison, average month revenue per active household seller is much more stable, with slight decrease in PL and ML than in no-regulation and VC.

Panel B shows that the average rating score per active NANA food seller declined steadily over the four periods but increased for household sellers. As for average sales price (Panel C), it tended to increase for NANA food sellers from no-regulation to PL, but dropped back during PL and ML. The trend is almost reversed for household sellers, with the average sales price at roughly the same level during ML as in the no-regulation period. Finally, an active NANA food seller had a greater number of active listings during PL and ML than before, while the number of active listings declined slightly for an active household seller in the same time frame.

All these comparisons are raw averages across the sampled sellers, which may not be exactly comparable at the individual seller level. In Section 4, we will conduct synthetic control matching for each individual NANA seller to ensure comparability. 


\section{Main Results from Synthetic Control Matching}

So far, we have documented the supply of FSL licenses among NANA sellers and consumer response to such licensing information. However, these descriptive statistics do not control for what else was happening on the platform at the same time, and they are subject to missing values in licensing information. A more rigorous evaluation of FSL should compare NANA food with non-food categories and not depend on the observed licensing status. In this section, we do so by synthetic control matching. We adopt synthetic control matching rather than difference-in-differences (DID) because NANA food and non-food categories were different even before FSL. We start by describing the synthetic control method, and then we present evidence at the category level and seller level separately.

\subsection{Method}

Both synthetic control matching and DID rely on control units to tease out the treatment effect from the treated units' over-time variations. But different from DID, synthetic control matching does not require parallel pre-treatment trends for treated units and control units. Instead, the method puts weights on the control donor pool and constructs a synthetic unit that can perfectly match the pre-treatment trend for the treated unit Abadie and Gardeazabal (2003) and Abadie et al. (2010)).

Synthetic control matching is developed for case studies with one outcome variable, but we consider multiple outcome variables, including seller count, average price, seller quality, etc. Ideally, we want to find the synthetic control unit to be the same as the treated across all outcome variables. But when we try to match all variables jointly, the pre-treatment matching quality is uneven across outcome variables $9^{9}$ Ex ante, it is difficult to judge which outcome variable should receive more weight in the overall quality of joint matching. In light of this, we apply synthetic control matching to each outcome variable independently.

We start with category-level analysis for the seven outcome variables listed in Table 1 . This is to understand the average treatment effects of the FSL on NANA food. For each outcome variable, we look for a synthetic control unit from the donor pool of the 134 nonfood categories, including 7 household categories and 127 non-food non-household categories. We match the outcome variables during no-regulation and keep the weights unchanged for the periods of $\mathrm{VC}, \mathrm{PL}$ and ML.

\footnotetext{
${ }^{9}$ Robbins et al. (2017) proposed a micro-synthetic control method for multiple outcome variables and an RStudio package microsynth.R. We have tried the new method jointly matching all outcome variables.
} 
We then conduct a seller-level analysis to understand the heterogeneous treatment effects on different types of sellers. For each of the 1,926 NANA sellers in our random sample, we find the synthetic control unit from the donor pool of 5,721 individual sellers in the 7 household categories. Based on data from the no-regulation period, we perform synthetic control matching on each of the four outcome variables separately: seller's monthly GMV, average rating score, average sales prices, and the number of active listings.

We do not have a balanced panel for average sales price if a seller has zero sales in a month because we calculate sellers' average sales price from GMV and quantities sold. To deal with it, we aggregate the seller-month-level prices to seller-quarter-level prices and drop sellers who still have unbalanced quarterly prices during no-regulation. Also, we observe missing rating scores if a seller has no sales in a month. We impute the missing value as the seller's non-missing average rating score in the latest previous month with positive sales, because the rating score is mechanically calculated based on purchases in the last six months according to the platform. Therefore, the results for sellers' monthly GMV, average rating score, and the number of active listings are all unconditional on seller survival, but the result for average sales price is conditional on seller survival.

\subsection{Category-level results}

Figure 3 presents the effects of the FSL on NANA food over three treated periods (VC, PL and ML). To protect Alibaba's business secrets, we display only the relative difference between the treated unit and the synthetic control rather than their actual values.

Table 10 displays the treatment effects and the inference of the FSL on the food category in the first month of each treatment period. The inference is computed from bootstrapping. In particular, we conduct the synthetic control for each of the control categories while using all other categories as the donor pool. This gives us a distribution of treatment effects under the null hypothesis of zero effect. We use the distribution to calculate p-values. For the positive treatment effect, its one-sided p-value is the probability that placebo effects are above the treatment effect. For the negative treatment effect, its one-sided p-value is the probability that placebo effects are below the treatment effect.

Consistent with the data summary in Table 1, seller count in NANA food has a $15.4 \%$ increase in the first month of $\mathrm{VC}$ but a $1.4 \%$ drop in the first month of ML, all relative to noregulation. Most of the time, the effect on seller count is not statistically different from zero. The HHI increase in NANA food started in VC but became statistically significant in PL and ML. Average rating score per seller was on the upper end of the confidence interval during VC, 
PL and the first half of ML, and eventually became significantly positive in the second half of ML 10 In the meantime, the percentage of returns due to quality and counterfeit problems dropped significantly. For these two variables, the quality of synthetic control matching is not as good as other outcome variables, partly because they are designed to capture small probability events, partly because their values for NANA food were extraordinarily high in part of 2014 (Table 1). The synthetic matching results also suggest that these two variables improved significantly even before the beginning of VC. We don't know the exact reason. If Alibaba had started to target the food category for quality issues before the official start of the FSL, the large improvement post FSL may not be fully attributable to the adoption of FSL. Overall, the three quality measures suggest that average seller quality has improved post FSL. As for average sales price, the point estimate is positive but rarely significant. Similarly, the effect of FSL on the platform's total GMV in NANA food was always within the $95 \%$ confidence interval. This suggests that the FSL does not hamper the long-run performance of the regulated market, probably because it has enhanced seller quality and market transparency on the platform.

\subsection{Seller-level results}

For each of the 1,926 randomly drawn NANA food sellers, we use synthetic control matching to find the comparable control from the sample of 5,721 randomly drawn household sellers. This is done for each of the four outcomes separately (i.e., monthly GMV, average rating score, average sales price conditional on sales, and number of unique active listings). In total, we obtain a treatment effect for each NANA food seller in each outcome.

Figure 4 presents the heterogeneous effects by sellers' pre-FSL GMV. We classify sellers into 10 groups based on the quantiles of their pre-FSL GMV in no-regulation. The x-axis shows the 10 groups from low to high. For each group, we show the distribution of the treatment effect with a whisker box plot. The bottom, middle, and top lines of the box show the 25th, 50th, and 75th percentiles. The two caps show the upper and lower adjacent values, which are the 25th (75th) percentile plus (minus) 1.5 times the interquartile range.

\footnotetext{
${ }^{10}$ The abnormal dip towards the end of VC was driven by Alibaba's algorithm change on rating score. Since late 2015, Alibaba's rating system no longer includes transactions in which the final transaction price is extremely low $(<5 \mathrm{RMB}$, equivalent to 80 cents in US\$). This policy applies to historical cumulative ratings and affects different categories differently depending on the price distribution specific to each category. Because food items are more likely to be of low price, this algorithm causes the average rating score to drop significantly in late 2015. However, average rating score is a six-month moving average, so the impact of this change attenuates over time. To the extent that it remains to affect food more than other categories, our synthetic control estimate may underestimate the effect of the FSL on sellers' rating score.
} 
Values within the caps and out of the box are mild outliers, and the dotted values outside the caps are extreme values. This graph is drawn for each of the four outcomes separately.

Figure 5 presents the heterogeneous effects of the FSL by sellers' pre-FSL reputation. Same as before, we classify the sampled sellers into 11 groups according to sellers' pre-FSL reputation based on Alibaba's definition for stars, crowns, and diamonds. For each group, we show the 25th, 50th, and 75th percentiles with the whisker box, the upper and lower adjacent values with two caps, and extreme outliers with dots.

Tables 11 and 12 show the point estimates for the median and 75th percentile of the individual treatment effects for each seller group, with p-value. The inference is drawn from bootstrapping. In particular, we randomly draw $30 \%(1,716)$ sellers from the 5,721 individual household sellers and use them as a hypothetical treatment group. We then compute the placebo treatment effect for each seller and each outcome, and group these "treated" placebo sellers into 10 groups by their pre-FSL GMV (or 11 groups by pre-FSL reputation). For each group, we can compute the placebo median effect and the placebo 75th percentile effect. Repeating this 100 times, we compute the one-sided p-value for the treatment median effect and the treatment 75 th percentile effect. For the positive treatment effect, its one-sided p-value is the probability that placebo effects are above the treatment effect. For the negative treatment effect, its one-sided p-value is the probability that placebo effects are below the treatment effect.

Among the multiple treatment periods, we only show the results for ML because that is the period with the most dramatic changes according to our category analysis. Results suggest that sellers in the top decile of pre-FSL GMV are more able to survive and grow their GMV in the ML period than sellers in all the other deciles; they are also more able to expand the number of listings in ML than other sellers. That being said, even the top decile sellers suffer from a large, significant drop in GMV at the median and 75th percentile, suggesting that the true dynamics are more complicated than just that the largest survive and grow. As shown in Figure 4, each decile has some outlier sellers enjoying a significant GMV growth post FSL, which in combination drives the significant increase of HHI in NANA food (Figure 3). As for average rating and price, sellers of all groups have positive median effects, and there is no obvious relationship between the magnitude of these effects and pre-FSL GMV. This suggests that ML could encourage higher seller quality and allow higher price regardless of the seller's pre-treatment size, if they can survive. When we group sellers by their pre-FSL reputation, the heterogeneity is similar.

Figure 6 compares new entrants in NANA food with new entrants in the seven household 
categories. A seller is counted new in month $t$ if she opened the store on Alibaba after January 2014 and still has sales in or after month $t$. By this definition, the new seller count is cumulative since January 2014, conditional on survival at the study time. Figure 6 is limited to NANA food and household categories because we do not have individual seller data to track seller entry time in other categories. For the same reason, we do not have enough non-food categories to construct category-level synthetic control for the pattern of seller entry. That said, the raw comparison between NANA food and household categories is still informative.

Over time, Figure 6a displays the percentage of new sellers among all surviving sellers in NANA food, relative to household categories. For example, if at month $t, \mathrm{x} \%$ of all sellers active in the household categories are new since January 2014 and $(x+1) \%$ of NANA food sellers are new, then the graph plots $1 \%$ for month $t$. The three straight lines indicate the start of $\mathrm{VC}, \mathrm{PL}$ and $\mathrm{ML}$, respectively.

In short, Figure 6a shows relatively fewer new sellers in NANA food after the beginning of ML, although more entries occurred in NANA food during VC and PL. The latter could happen if $\mathrm{VC}$ and PL prompted new non-licensable sellers to take the last opportunity to sell NANA food without a license.

Figure 6b plots the new entrants' average rating score three months after entry, in NANA food relative to the household categories. Throughout the whole sample period (January 2014 to June 2018), new entrants in NANA food tend to have higher average rating scores than similar entries into household categories, at an average of 0.035 . This gap became somewhat smaller in the first half of ML and larger in the second half of ML. Recall from the categorylevel analysis that the FSL has a positive effect on seller quality, especially during PL and ML. Figure 6a and Figure 6b suggest that such quality improvement is unlikely driven by new entrants, as NANA food saw fewer new entrants than household categories in the ML period and the quality gap of the new entrants in NANA food and household categories did not rise significantly during PL and ML.

\section{Conclusion}

We examine how the 2015 Food Safety Law (FSL) affects e-commerce in China. Because the FSL was rolled out progressively, we have a rare opportunity to observe a gradual transition from voluntary certification to partial licensing and mandatory licensing.

We find that FSL licensing provides an opportunity for younger and less reputable sellers 
to stand out as quality food sellers, and consumers respond positively to the display of the FSL license on the platform. In addition, as compared to non-food categories, it seems that the FSL has improved average seller quality in the regulated food category without driving down its overall GMV or raising its average sales price one year after the full enforcement of the FSL. These findings suggest that the FSL may have brought substantial benefits to the market.

In addition, anecdotes suggest that enforcement and compliance costs are non-trivial. Because the FSL is an offline licensing requirement for online sellers, enforcement entails both offline resources from local governments and online resources from the platform. Besides enforcement costs, the cost of compliance is likely non-trivial for at least some food sellers, which may explain why larger and reputable sellers are more likely to obtain the FSL license despite the fact that consumers respond more positively to the licensing of younger and less reputable sellers. Another cost of the FSL may be reflected in the increased seller concentration. In our sample period, the higher concentration has not led to detectable price increases, but we do observe fewer new entrants into NANA food in the ML period, as compared to entrants in the household categories. It remains to be seen whether the higher barrier to entry due to the FSL would generate more costs for market competition in the future.

\section{References}

Abadie, A., A. Diamond, and J. Hainmueller (2010). Synthetic control methods for comparative case studies: Estimating the effect of california's tobacco control program. Journal of the American Statistical Association 105(490), 493-505.

Abadie, A. and J. Gardeazabal (March 2003). The economic costs of conflict: A case study of the basque country. The American Economic Review 93(1), 113-132.

Adams III, A. F., R. B.Ekelund Jr., and J. D. Jackson (January 2003). Occupational licensing of a credence good: The regulation of midwifery. Southern Economic Journal 69(3), 659675.

Bajari, P. and A. Hortacsu (2004). Economic insights from internet auctions. Journal of Economic Literature 42(2), 457-48. 
Cai, H., G. Z. Jin, C. Liu, and L. Zhou (2014). More trusting, less trust? an investigation of early e-commerce in china. NBER working paper No.18961.

Chen, M. and K. Serfes (2012). Minimum quality standard regulation under imperfect quality observability. Journal of Regulatory Economics 41, 269-291.

Dai, W. D., G. Z. Jin, J. Lee, and M. Luca (2018). Aggregation of consumer ratings: an application to yelp.com. Quantitative Marketing and Economics 16(3), 289-339.

Dellarocas, C. (2003). The digitization of word of mouth: Promise and challenges of online feedback mechanisms. Management Science 49(10), 1407-1424.

Dranove, D. and G. Z. Jin (December 2010). Quality disclosure and certification: Theory and practice. Journal of Economic Literature (4), 936-963.

Farronato, C., A. Fradkin, B. Larsen, and E. Brynjolfsson (2020). Consumer protection in an online world: An analysis of occupational licensing. NBER Working Paper No. 26601.

Garella, P. G. and E. Petrakis (2008). Minimum quality standards and consumers' information. Economic Theory 36(2), 283-302.

Hall, J., J. Hicks, M. M. Kleiner, and R. Solomon (2019). Occupational licensing of uber drivers. Working paper.

Hui, X., M. Saeedi, Z. Shen, and N. Sundaresan (2016). Reputation and regulations: Evidence from ebay. Management Science.

Jin, G. Z. and A. Kato (July 2007). Dividing online and offline: A case study. Review of Economic Studies 74(3), 981-1004.

Kleiner, M. M. and R. T. Kudrle (2000). Does regulation affect economic outcomes? the case of dentistry. Journal of Law and Economics 43(2), 547-82.

Kleiner, M. M. and R. M. Todd (2009). Mortgage broker regulations that matter: Analyzing earnings, employment and outcomes for consumers. In D. Autor (Ed.), Labor Market Intermediation, pp. 183-234. MIT and University of Chicago Press.

Law, M. T. and S. Kim (2005). Specialization and regulation: The rise of professionals and the emergence of occupational licensing regulation. The Journal of Economic History $65(3), 723-756$. 
Law, M. T. and M. S. Marks (2009). Effects of occupational licensing laws on minorities: Evidence from the progressive era. Journal of Law and Economics 52(2), 351-366.

Leland, H. E. (December 1979). Quacks, lemons and licensing: A theory of minimum quality standards. Journal of Political Economy 87(6), 1328-1346.

Lewis, G. (2011). Asymmetric information, adverse selection and online disclosure: The case of ebay motors. American Economic Review 101(4), 1535-46.

Luca, M. (2017). Designing online marketplaces: Trust and reputation mechanisms. In L. Greenstein and Stern (Eds.), Innovation Policy and the Economy, Volume 17. The MIT Press.

Luca, M. and G. Zervas (2016). Fake it till you make it: Reputation, competition and yelp review fraud. Management Science 62(12), iv-vii, 3393-3672.

Mayzlin, D., Y. Dover, and J. Chevalier (2014). Promotional reviews: An empirical investigation of online review manipulation. American Economic Review 104(8), 2421-55.

Pashigian, B. P. (April 1979). Occupational licensing and the interstate mobility of professionals.

Robbins, M. W., J. Saunders, and B. Kilmer (2017). A framework for synthetic control methods with high-dimensional, micro-level data: Evaluating a neighborhood-specific crime intervention. Journal of the American Statistical Association 112(517), 109-126.

Roberts, J. W. (2011). Can warranties substitute for reputations? American Economic Journal: Microeconomics 3(3), 69-85.

Ronnen, U. (1991). Minimum quality standards, fixed costs and competition. The Rand Journal of Economics 22(4), 490-504.

Scarpa, C. (1998). Minimum quality standards with more than two firms. International Journal of Industrial Organization 16(5), 665-676.

Shapiro, C. (October 1986). Investment, moral hazard and occupational licensing. The Review of Economic Studies 53(5), 843-862.

Shepard, L. (1978). Licensing restrictions and the cost of dental care. The Journal of Law and Economics 21(1), 187-201. 
Tadelis, S. (2016). Reputation and feedback systems in online platform markets. Annual Review of Economics 8(1), 321-340. 


\section{Appendix}

\subsection{Tables}

Table 1: Summary Statistics of Cateogry-level Sample

\begin{tabular}{|c|c|c|c|c|c|c|}
\hline & $\begin{array}{l}\text { NANA } \\
\text { Food }\end{array}$ & Household & $\begin{array}{c}\text { Non-food } \\
\text { Non-household }\end{array}$ & $\begin{array}{l}\text { NANA } \\
\text { Food }\end{array}$ & Household & $\begin{array}{c}\text { Non-food } \\
\text { Non-household }\end{array}$ \\
\hline & \multicolumn{3}{|c|}{$\begin{array}{c}\text { Panel A: Total Number of } \\
\text { Unique Active Sellers }\end{array}$} & \multicolumn{3}{|c|}{ Panel B: Category HHI } \\
\hline No Regulation & 0.112 & -0.171 & 0.020 & -0.356 & -0.395 & 0.057 \\
\hline Voluntary Certification & 0.687 & -0.048 & -0.006 & -0.188 & -0.333 & 0.046 \\
\hline Partial Licensing & 0.697 & -0.009 & -0.011 & 0.265 & -0.443 & 0.052 \\
\hline \multirow[t]{2}{*}{ Mandatory Licensing } & -0.021 & 0.215 & -0.027 & 1.886 & -0.395 & 0.016 \\
\hline & \multicolumn{3}{|c|}{$\begin{array}{c}\text { Panel C: Avg. Rating Score } \\
\text { per Active Seller }\end{array}$} & \multicolumn{3}{|c|}{$\begin{array}{l}\text { Panel D: Avg. Reputation } \\
\text { per Active Seller }\end{array}$} \\
\hline No Regulation & 0.885 & 0.395 & -0.066 & -0.127 & 1.264 & -0.159 \\
\hline Voluntary Certification & 0.586 & 0.177 & -0.033 & -0.277 & 0.853 & -0.104 \\
\hline Partial Licensing & 1.495 & -0.577 & 0.046 & -0.125 & 0.447 & -0.055 \\
\hline \multirow[t]{2}{*}{ Mandatory Licensing } & 1.337 & -0.320 & 0.016 & 0.218 & 0.299 & -0.042 \\
\hline & \multicolumn{3}{|c|}{$\begin{array}{l}\text { Panel E: Avg. \%Returns due to } \\
\text { Quality Problem per Active seller }\end{array}$} & \multicolumn{3}{|c|}{$\begin{array}{l}\text { Panel F: Avg. \%Returns due to } \\
\text { Counterfeits per Active Seller }\end{array}$} \\
\hline No Regulation & 2.036 & 0.510 & -0.102 & 4.719 & 0.012 & -0.087 \\
\hline Voluntary Certification & -0.645 & 1.714 & -0.206 & -0.221 & 0.327 & -0.038 \\
\hline Partial Licensing & -0.782 & 1.640 & -0.194 & -0.431 & 0.076 & -0.002 \\
\hline \multirow[t]{2}{*}{ Mandatory Licensing } & -1.520 & 0.959 & -0.094 & -1.183 & -0.212 & 0.048 \\
\hline & \multicolumn{3}{|c|}{$\begin{array}{l}\text { Panel G: Avg. Price } \\
\text { per Active Listing }\end{array}$} & \multicolumn{3}{|c|}{ Panel H: Total GMV } \\
\hline No Regulation & -0.329 & -0.346 & 0.050 & -0.282 & -0.584 & 0.079 \\
\hline Voluntary Certification & -0.327 & -0.348 & 0.050 & -0.352 & -0.574 & 0.080 \\
\hline Partial Licensing & -0.317 & -0.336 & 0.048 & -0.339 & -0.530 & 0.074 \\
\hline Mandatory Licensing & -0.311 & -0.325 & 0.047 & -0.313 & -0.413 & 0.058 \\
\hline
\end{tabular}

Notes: All statistics are averages across categories over months. To avoid revealing Alibaba's business secrets, all numbers are normalized by the platform-level mean and standard deviation. For example, 0.112 in Panel A means that the number of sellers in the NANA food category is 0.112 standard deviation above the platform-wide mean during no regulation. 
Table 2: Summary Statistics for a Random Sample of NANA Food Sellers

\begin{tabular}{lccc}
\hline \hline & Mean & Median & Std. Dev. \\
\hline No. of Sellers & 1,926 & - & - \\
\#Seller-Month Observations & 41,272 & - & - \\
& & & \\
\#Sellers obtaining a license & 335 & - & - \\
\#Sellers obtaining a license during VC & 96 & - & - \\
\#Sellers obtaining a license during PL & 129 & - & - \\
\#Sellers obtaining a license during ML & 110 & - & - \\
& & & \\
\#Sellers exiting the market & 1,613 & - & - \\
\#Sellers exiting the market during No Regulation & 292 & - & - \\
\#Sellers exiting the market during VC & 387 & - & - \\
\#Sellers exiting the market during PL & 419 & - & - \\
\#Sellers exiting the market during ML & 828 & - & - \\
& & & \\
Seller Monthly GMV (\$) & 4,929 & 268 & 42,177 \\
Seller Monthly No. of Orders & 393 & 12 & 2,724 \\
Seller Monthly No. of Buyers & 437 & 13 & 3,034 \\
Seller Monthly Quantities & 1,376 & 46 & 11,091 \\
& & & \\
Sellers' Reputation & 21,932 & 2,419 & 81,070 \\
\#Low Reputation Sellers (<=250 Pos. Ratings) & 669 & - & - \\
\#High Reputation Sellers (>250 Pos. Ratings) & 1,257 & - & - \\
& & & \\
Sellers' Age (Months) & 21.89 & 10 & 27.55 \\
\#Young (Pre-treat Age <=12 Months) & 641 & - & - \\
\#Old sellers (Pre-treat Age $>12$ Months) & 1,284 & - & - \\
\hline \hline
\end{tabular}

Notes: This table summarizes the random sample of 1,926 individual sellers who have sales in NANA food for at least three months during no regulation. A seller's reputation is defined by Alibaba as her total count of positive consumer feedback minus total count of negative feedback. GMV is translated from China RMB to US dollars using the exchange rate of 6 . 
Table 3: Comparing NANA Food Sellers With and Without Licensing Information

\begin{tabular}{|c|c|c|c|c|}
\hline & $\begin{array}{l}\text { Sellers with } \\
\text { no } \\
\text { License Data }\end{array}$ & $\begin{array}{c}\text { ales Post ML } \\
\text { with } \\
\text { License Data }\end{array}$ & $\begin{array}{l}\text { Sellers with } \\
\text { no } \\
\text { License Data }\end{array}$ & $\begin{array}{c}\text { Sales in } 2018 \\
\text { with } \\
\text { License Data }\end{array}$ \\
\hline No. of Sellers & 598 & 303 & 135 & 247 \\
\hline Pre-FSL Monthly GMV $(\$)$ & 2502.25 & 4523.71 & 6565.82 & 5137.24 \\
\hline Pre-FSL Monthly Reputation & 6315.19 & 18146.22 & 12221.09 & 19380.29 \\
\hline Pre-FSL Avg. Age (Months) & 276.17 & 400.78 & 306.89 & 416.63 \\
\hline Monthly GMV (\$) & 7803.13 & 7066.75 & 18263.28 & 7815.51 \\
\hline Monthly No. of Buyers & 386.89 & 678.55 & 956.34 & 761.24 \\
\hline Monthly No. of Orders & 425.329 & 762.25 & 1051.54 & 856.30 \\
\hline Monthly Quantities & 1081.003 & 2511.21 & 2032.633 & 2829.15 \\
\hline No. of Active Months & 29.59 & 44.42 & 45.51 & 46.39 \\
\hline Post-ML Monthly GMV (\$) & 15294.48 & 8054.57 & 26887.98 & 8640.94 \\
\hline Post-ML Monthly No. of Buyers & 688.29 & 741.54 & 1262.79 & 798.94 \\
\hline Post-ML Monthly No. of Orders & 763.05 & 850.65 & 1398.74 & 917.22 \\
\hline Post-ML Monthly Quantities & 1582.52 & 2331.55 & 2485.84 & 2515.97 \\
\hline Post-ML No. of Active Months & 13.71 & 23.50 & 24.68 & 25.40 \\
\hline
\end{tabular}

Notes: This table presents the average pre-FSL attributes and the average outcome variables by sellers with and without FSL license information, conditional on having NANA food sales post mandatory licensing (ML) or post 2018. As we miss the licensing record of some sellers, those that have sales post ML but no license are subject to a missing-data problem. Pre-FSL GMV and pre-FSL reputation are computed as monthly averages during no regulation, taking into account inactive months. During inactive months, the GMV is imputed with zero and the reputation is imputed with the latest reputation up to that inactive month. GMV is translated from China RMB to US dollars using the exchange rate of 6 . 
Table 4: Duration Model Result for NANA Food Sellers Displaying an FSL License

\begin{tabular}{|c|c|c|c|c|}
\hline \multirow[t]{3}{*}{ Covariates } & \multicolumn{2}{|c|}{ Full Sample } & \multicolumn{2}{|c|}{$\begin{array}{c}\text { Sellers with Valid } \\
\text { Licensing Data Only }\end{array}$} \\
\hline & Hazard & Std. & Hazard & Std. \\
\hline & Ratio & Err. & Ratio & Err. \\
\hline Log of pre-FSL GMV $\times$ Voluntary Certification & $1.356^{* * *}$ & $(0.098)$ & $1.192^{* *}$ & $(0.082)$ \\
\hline$\times$ Partial Licensing & $1.180^{* * *}$ & $(0.051)$ & 1.032 & $(0.048)$ \\
\hline$\times$ Mandatory Licensing & $0.783^{* * *}$ & $(0.039)$ & 0.841 & $(0.042)$ \\
\hline Log of pre-FSL Reputation $\times$ Voluntary Certification & $1.353^{* * *}$ & $(0.102)$ & $1.236^{* *}$ & $(0.091)$ \\
\hline$\times$ Partial Licensing & $1.145^{*}$ & $(0.052)$ & 1.087 & $(0.057)$ \\
\hline$\times$ Mandatory Licensing & 1.011 & $(0.053)$ & 0.925 & $(0.044)$ \\
\hline No. of Subjects & 1,631 & & 331 & \\
\hline No. of Observations & 26,453 & & 4,491 & \\
\hline Log-likelihood & -1664.183 & & -1289.506 & \\
\hline
\end{tabular}

Notes: This table presents the Cox proportional hazard regression results for NANA food sellers' propensity of displaying a license. The pre-FSL GMV and the pre-FSL reputation are both monthly averages including inactive months in 2014. For each inactive month, we impute the seller's GMV with zero and impute her reputation with her latest reputation up to that month. Standard errors are in parentheses, ${ }^{*} \mathrm{p}<0.05^{* *} \mathrm{p}<0.01 * * * \mathrm{p}<0.001$. The estimation drops three sellers with missing reputation measures in 2014.

Table 5: Duration Model Result for NANA Food Sellers Exiting the Market

\begin{tabular}{|c|c|c|}
\hline Covariates & Hazard Ratio & Std. Err. \\
\hline Log of pre-FSL GMV $\times$ Voluntary Certification & $1.508^{* * *}$ & $(0.031)$ \\
\hline$\times$ Partial Licensing & $1.063^{* *}$ & $(0.019)$ \\
\hline$\times$ Mandatory Licensing & $0.695^{* * *}$ & $(0.012)$ \\
\hline Log of pre-FSL Reputation $\times$ Voluntary Certification & $0.765^{* * *}$ & $(0.020)$ \\
\hline$\times$ Partial Licensing & $0.943^{*}$ & $(0.022)$ \\
\hline$\times$ Mandatory Licensing & $1.047^{*}$ & $(0.022)$ \\
\hline No. of Subjects & 1,631 & \\
\hline No. of Observations & 34,028 & \\
\hline Log-likelihood & -7835.657 & \\
\hline
\end{tabular}

Notes: This table presents the Cox proportional hazard regression results for NANA food sellers' behavior of exiting the marketplace. The pre-FSL GMV and the pre-FSL reputation are both the monthly average including inactive months in 2014. For each inactive month, we impute the seller's GMV with zero and impute her reputation with her latest reputation up to that month. Standard errors are in parentheses, ${ }^{*} \mathrm{p}<0.05{ }^{* *} \mathrm{p}<0.01{ }^{* * *} \mathrm{p}<0.001$. The estimation drops three sellers with missing reputation measures in 2014. 
Table 6: Demand Responses to NANA Food Sellers' License Status

\begin{tabular}{|c|c|c|c|c|c|}
\hline & \multicolumn{5}{|c|}{ Dependent Variable } \\
\hline & \multicolumn{4}{|c|}{ Log of Sellers' } & \multirow{3}{*}{$\begin{array}{l}\text { Dummy of } \\
\text { Pos. Sales } \\
(5)\end{array}$} \\
\hline & GMV & \#Orders & \#Buyers & Quantities & \\
\hline & (1) & $(2)$ & $(3)$ & (4) & \\
\hline \multicolumn{6}{|l|}{ Disclosing a License } \\
\hline$\times$ Voluntary Certification & $\begin{array}{c}0.304^{* * *} \\
(0.088)\end{array}$ & $\begin{array}{c}0.272^{* * *} \\
(0.077)\end{array}$ & $\begin{array}{c}0.276^{* * *} \\
(0.076)\end{array}$ & $\begin{array}{c}0.331^{* * *} \\
(0.089)\end{array}$ & $\begin{array}{c}0.141^{* * *} \\
(0.021)\end{array}$ \\
\hline$\times$ Partial Licensing & $\begin{array}{c}0.538^{* * *} \\
(0.054)\end{array}$ & $\begin{array}{c}0.561^{* * *} \\
(0.047)\end{array}$ & $\begin{array}{c}0.559^{* * *} \\
(0.046)\end{array}$ & $\begin{array}{c}0.522^{* * *} \\
(0.055)\end{array}$ & $\begin{array}{c}0.310^{* * *} \\
(0.013)\end{array}$ \\
\hline$\times$ Mandatory Licensing & $\begin{array}{c}0.697^{* * *} \\
(0.033)\end{array}$ & $\begin{array}{c}0.680^{* * *} \\
(0.029)\end{array}$ & $\begin{array}{c}0.665^{* * *} \\
(0.029)\end{array}$ & $\begin{array}{c}0.618^{* * *} \\
(0.034)\end{array}$ & $\begin{array}{c}0.323^{* * *} \\
(0.007)\end{array}$ \\
\hline No. of Observations & 41,272 & 41,272 & 41,272 & 41,272 & 56,364 \\
\hline
\end{tabular}

Notes: This table presents consumers' demand responses to NANA food sellers' license status. All columns display the OLS estimates from a linear model with seller-level fixed effects and monthly dummies. Columns (1) to (4) use active seller-month observations, and column (5) includes inactive months. Standard errors are in parentheses, ${ }^{*} \mathrm{p}<0.05^{* *} \mathrm{p}<0.01 * * * \mathrm{p}<0.001$. 
Table 7: Heterogeneous Demand Responses to NANA Food Sellers' License Status By Age

\begin{tabular}{|c|c|c|c|c|c|}
\hline & \multicolumn{5}{|c|}{ Dependent Variable } \\
\hline & \multicolumn{4}{|c|}{ Log of Sellers' } & \multirow{2}{*}{$\begin{array}{l}\text { Dummy of } \\
\text { Pos. Sales }\end{array}$} \\
\hline & GMV & \#Orders & \#Buyers & Quantities & \\
\hline & $(1)$ & $(2)$ & $(3)$ & $(4)$ & $(5)$ \\
\hline & \multicolumn{5}{|c|}{ Panel A: Young Sellers } \\
\hline \multirow{3}{*}{$\begin{array}{l}\text { Disclosing a License } \\
\times \text { Voluntary Certification }\end{array}$} & & & & & \\
\hline & $0.498^{*}$ & $0.429^{*}$ & $0.437^{*}$ & $0.558^{*}$ & $0.183^{* *}$ \\
\hline & $(0.225)$ & $(0.196)$ & $(0.193)$ & $(0.228)$ & $(0.056)$ \\
\hline \multirow[t]{2}{*}{$\times$ Partial Licensing } & $0.867^{* * *}$ & $0.866^{* * *}$ & $0.867^{* * *}$ & $0.905^{* * *}$ & $0.293^{* * *}$ \\
\hline & $(0.136)$ & $(0.118)$ & $(0.116)$ & $(0.137)$ & $(0.032)$ \\
\hline \multirow[t]{2}{*}{$\times$ Mandatory Licensing } & $1.014^{* * *}$ & $1.099 * * *$ & $1.084^{* * *}$ & $1.028^{* * *}$ & $0.274^{* * *}$ \\
\hline & $(0.078)$ & $(0.068)$ & $(0.067)$ & $(0.079)$ & $(0.017)$ \\
\hline \multirow[t]{2}{*}{ No. of Observations } & 10,736 & 10,736 & 10,736 & 10,736 & 16,399 \\
\hline & \multicolumn{5}{|c|}{ Panel B: Old Sellers } \\
\hline \multirow{3}{*}{$\begin{array}{l}\text { Disclosing a License } \\
\times \text { Voluntary Certification }\end{array}$} & & & & & \\
\hline & $0.284^{* *}$ & $0.241^{* *}$ & $0.245^{* *}$ & $0.294^{* *}$ & $0.121^{* * *}$ \\
\hline & $(0.095)$ & $(0.083)$ & $(0.082)$ & $(0.096)$ & $(0.022)$ \\
\hline \multirow[t]{2}{*}{$\times$ Partial Licensing } & $0.485^{* * *}$ & $0.500 * * *$ & $0.498^{* * *}$ & $0.456^{* * *}$ & $0.293^{* * *}$ \\
\hline & $(0.059)$ & $(0.051)$ & $(0.050)$ & $(0.059)$ & $(0.013)$ \\
\hline \multirow[t]{2}{*}{$\times$ Mandatory Licensing } & $0.679^{* * *}$ & $0.627^{* * *}$ & $0.613^{* * *}$ & $0.564^{* * *}$ & $0.318^{* * *}$ \\
\hline & $(0.037)$ & $(0.032)$ & $(0.032)$ & $(0.038)$ & $(0.008)$ \\
\hline No. of Observations & 30,536 & 30,536 & 30,536 & 30,536 & 39,965 \\
\hline
\end{tabular}

Notes: This table presents heterogeneous demand responses to NANA food sellers' license status, by young and old sellers. All columns display the estimates from a linear model with seller-level fixed effects and monthly dummies. Columns (1) to (4) use the sample of active seller-month observations, and column (5) includes inactive months. Young sellers are defined as those who have an open store in the marketplace for less than 12 months until December 2014, and old sellers are those who have an open store in the marketplace for more than 12 months until December 2014. Standard errors are in parentheses, ${ }^{*} \mathrm{p}<0.05^{* *} \mathrm{p}<0.01 * * * \mathrm{p}<0.001$. 
Table 8: Heterogeneous Demand Responses to NANA Food Sellers' License Status By Reputation

\begin{tabular}{|c|c|c|c|c|c|}
\hline & \multicolumn{5}{|c|}{ Dependent Variable } \\
\hline & \multicolumn{4}{|c|}{ Log of Sellers' } & \multirow{3}{*}{$\begin{array}{l}\text { Dummy of } \\
\text { Pos. Sales } \\
(5)\end{array}$} \\
\hline & GMV & \#Orders & \#Buyers & Quantities & \\
\hline & (1) & $(2)$ & (3) & (4) & \\
\hline & \multicolumn{5}{|c|}{ Panel A: Low Reputation } \\
\hline \multirow{3}{*}{$\begin{array}{l}\text { Disclosing a License } \\
\times \text { Voluntary Certification }\end{array}$} & & & & & \\
\hline & 0.634 & 0.439 & 0.479 & 0.661 & $0.230^{*}$ \\
\hline & $(0.384)$ & $(0.301)$ & $(0.293)$ & $(0.383)$ & $(0.106)$ \\
\hline$\times$ Partial Licensing & $\begin{array}{c}0.715^{* * *} \\
(0.202)\end{array}$ & $\begin{array}{c}0.655^{* * *} \\
(0.158)\end{array}$ & $\begin{array}{c}0.656^{* * *} \\
(0.154)\end{array}$ & $\begin{array}{c}0.674^{* * *} \\
(0.201)\end{array}$ & $\begin{array}{c}0.313^{* * *} \\
(0.051)\end{array}$ \\
\hline \multirow[t]{2}{*}{$\times$ Mandatory Licensing } & $1.311^{* * *}$ & $1.480^{* * *}$ & $1.502^{* * *}$ & $1.311^{* * *}$ & $0.444^{* * *}$ \\
\hline & $(0.112)$ & $(0.088)$ & $(0.085)$ & $(0.111)$ & $(0.026)$ \\
\hline \multirow[t]{2}{*}{ No. of Observations } & 7,966 & 7,966 & 7,966 & 7,966 & 14,775 \\
\hline & \multicolumn{5}{|c|}{ Panel B: High Reputation } \\
\hline \multirow{2}{*}{$\begin{array}{l}\text { Disclosing a License } \\
\times \text { Voluntary Certification }\end{array}$} & & & & & \\
\hline & $0.282^{* *}$ & $0.253^{* *}$ & $0.254^{* *}$ & $0.305^{* * *}$ & $0.098^{* * *}$ \\
\hline \multirow[t]{2}{*}{$\times$ Partial Licensing } & $0.548^{* * *}$ & $0.564^{* * *}$ & $0.564^{* * *}$ & $0.537^{* * *}$ & $0.252^{* * *}$ \\
\hline & $(0.057)$ & $(0.050)$ & $(0.050)$ & $(0.057)$ & $(0.012)$ \\
\hline \multirow{2}{*}{$\times$ Mandatory Licensing } & $0.675^{* * *}$ & $0.640^{* * *}$ & $0.622^{* * *}$ & $0.593^{* * *}$ & $0.261^{* * *}$ \\
\hline & $(0.035)$ & $(0.031)$ & $(0.031)$ & $(0.036)$ & $(0.007)$ \\
\hline No. of Observations & 33306 & 33306 & 33306 & 33306 & 41,598 \\
\hline
\end{tabular}

Notes: This table presents heterogeneous demand responses to NANA food sellers' license status by low- and high-reputation sellers. All columns display the estimates from a linear model with seller-level fixed effects and monthly dummies. Columns (1) to (4) use active seller-month observations, and column (5) includes inactive months. Low-reputation sellers are defined as those with the lowest level of stars granted by Alibaba during the no-regulation period, and the high-reputation sellers are those above the lowest level of stars during the no-regulation period. Standard errors are in parentheses, ${ }^{*} \mathrm{p}<0.05 * * \mathrm{p}<0.01 * * * \mathrm{p}<0.001$. 
Table 9: Summary Statistics of NANA Food and Household Seller Samples

\begin{tabular}{lcc}
\hline \hline & NANA Food Sellers & Household Sellers \\
\cline { 2 - 3 } No Regulation & 0.115 & -0.039 \\
Voluntary Certification & 0.089 & -0.035 \\
Partial Licensing & 0.161 & -0.058 \\
Mandatory Licensing & 0.187 & -0.046 \\
& & \\
No Regulation & Panel B: Seller Rating Score \\
Voluntary Certification & 0.207 & -0.070 \\
Partial Licensing & 0.170 & -0.067 \\
Mandatory Licensing & 0.126 & -0.046 \\
& 0.118 & -0.030 \\
& & \\
No Regulation & Panel C: Sellers & Price \\
Voluntary Certification & 0.079 & -0.027 \\
Partial Licensing & 0.090 & -0.035 \\
Mandatory Licensing & 0.152 & -0.055 \\
& 0.114 & -0.028 \\
& & \\
No Regulation & Panel D: Number of Active Listings \\
Voluntary Certification & -0.005 & 0.002 \\
Partial Licensing & -0.022 & 0.009 \\
Mandatory Licensing & 0.083 & -0.030 \\
\hline \hline
\end{tabular}

Notes:This table presents the average outcome variables per active seller-month for the 1,926 NANA food sellers and 5,721 household sellers. To avoid revealing Alibaba's business secrets, all numbers are normalized by the sample mean and sample standard deviation in each month. 


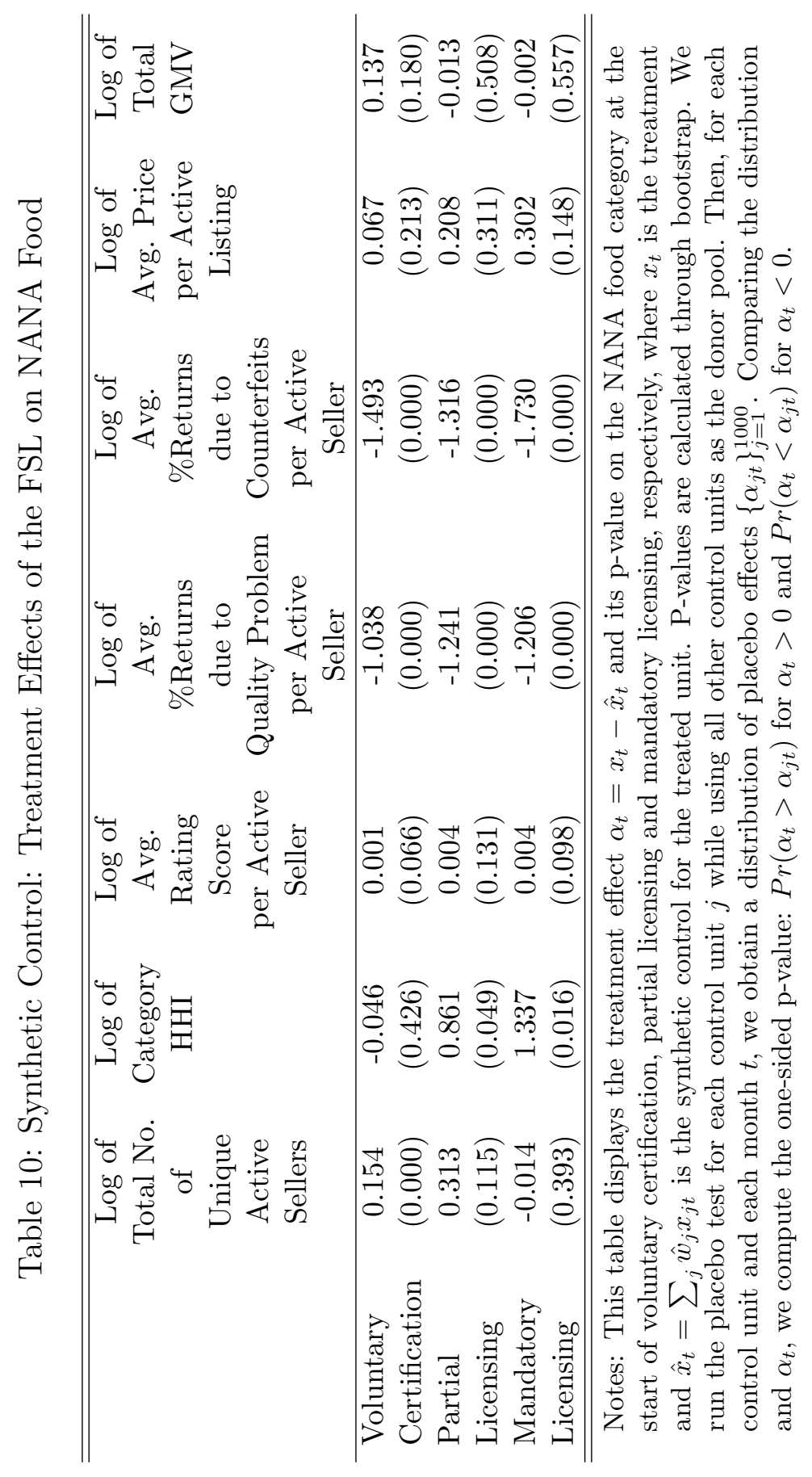


Table 11: Synthetic Control: Heterogeneous Effects of Mandatory Licensing on NANA Food Sellers by Pre-FSL GMV

\begin{tabular}{|c|c|c|c|c|c|c|c|c|}
\hline $\begin{array}{l}\text { Pre-FSL } \\
\text { GMV } \\
\text { Group }\end{array}$ & Median & P-value & 75 th Perc & P-value & Median & $\overline{\mathrm{P} \text {-value }}$ & 75 th Per & $\overline{P \text { P-value }}$ \\
\hline & \multicolumn{4}{|c|}{ Panel A: Sellers' GMV } & \multicolumn{4}{|c|}{ Panel B: Sellers' Rating Score } \\
\hline 1 & -1.000 & 0.000 & -1.000 & 0.000 & 0.004 & 0.000 & 0.011 & 0.000 \\
\hline 2 & -1.000 & 0.000 & -1.000 & 0.000 & 0.002 & 0.300 & 0.012 & 0.060 \\
\hline 3 & -1.000 & 0.000 & -0.974 & 0.110 & 0.002 & 0.290 & 0.012 & 0.160 \\
\hline 4 & -1.000 & 0.000 & -0.954 & 0.350 & 0.006 & 0.000 & 0.015 & 0.000 \\
\hline 5 & -1.000 & 0.000 & -0.965 & 0.000 & 0.004 & 0.000 & 0.013 & 0.010 \\
\hline 6 & -1.000 & 0.000 & -0.988 & 0.000 & 0.003 & 0.010 & 0.014 & 0.040 \\
\hline 7 & -0.999 & 0.000 & -0.924 & 0.000 & 0.005 & 0.000 & 0.015 & 0.010 \\
\hline 8 & -0.997 & 0.000 & -0.816 & 0.150 & 0.004 & 0.000 & 0.013 & 0.080 \\
\hline 9 & -0.976 & 0.000 & -0.783 & 0.000 & 0.004 & 0.150 & 0.012 & 0.560 \\
\hline \multirow[t]{2}{*}{10} & -0.948 & 0.000 & -0.679 & 0.000 & 0.005 & 0.000 & 0.011 & 0.170 \\
\hline & \multicolumn{4}{|c|}{$\begin{array}{l}\text { Panel C: Sellers' Price } \\
\text { Conditional on Survival }\end{array}$} & \multicolumn{4}{|c|}{$\begin{array}{c}\text { Panel D: \#Unique Active Listings } \\
\text { per Seller }\end{array}$} \\
\hline 1 & -0.049 & 0.000 & 0.045 & 0.990 & -1.000 & 0.000 & -1.000 & 0.000 \\
\hline 2 & -0.165 & 0.000 & 0.007 & 0.990 & -1.000 & 0.000 & -1.000 & 0.000 \\
\hline 3 & -0.144 & 0.110 & 0.084 & 0.860 & -1.000 & 0.000 & -0.766 & 0.020 \\
\hline 4 & -0.181 & 0.050 & 0.018 & 1.000 & -1.000 & 0.000 & -0.855 & 0.000 \\
\hline 5 & -0.267 & 0.010 & 0.021 & 0.970 & -1.000 & 0.000 & -0.834 & 0.000 \\
\hline 6 & -0.175 & 0.110 & 0.341 & 0.010 & -1.000 & 0.000 & -0.861 & 0.000 \\
\hline 7 & -0.106 & 0.580 & 0.543 & 0.010 & -0.965 & 0.050 & -0.185 & 0.370 \\
\hline 8 & -0.059 & 0.960 & 0.768 & 0.000 & -0.949 & 0.000 & -0.179 & 0.140 \\
\hline 9 & -0.182 & 0.040 & 0.695 & 0.100 & -0.655 & 0.710 & 0.282 & 0.310 \\
\hline 10 & -0.200 & 0.210 & 0.897 & 0.000 & 0.309 & 0.000 & 1.851 & 0.000 \\
\hline
\end{tabular}

Notes: This table presents the median and 75th percentile of the effect of mandatory licensing, and their one-sided p-values for sellers in different percentiles of pre-FSL GMV. The pre-FSL GMV is computed as the monthly average during the no-regulation period taking into account sellers' inactive months, where a seller's missing GMV is imputed with zero. Each group contains 10 percent of sellers. The p-value is calculated by bootstrapping. 
Table 12: Synthetic Control: Heterogeneous Effects of Mandatory Licensing on NANA Food Sellers by Pre-FSL Reputation

\begin{tabular}{|c|c|c|c|c|c|c|c|c|}
\hline $\begin{array}{l}\text { Pre-FSL } \\
\text { Reputation } \\
\text { Group }\end{array}$ & Median & P-value & 75 th Perc & $\overline{\mathrm{P} \text {-value }}$ & Median & P-value & 75th Perc. & P-value \\
\hline & \multicolumn{4}{|c|}{ Panel A: Sellers' GMV } & \multicolumn{4}{|c|}{ Panel B: Sellers' Rating Score } \\
\hline 1 & -1.000 & 0.000 & -1.000 & 0.000 & -0.009 & 0.940 & 0.004 & 0.110 \\
\hline 2 & -1.000 & 0.000 & -1.000 & 0.000 & -0.009 & 0.840 & 0.011 & 0.000 \\
\hline 3 & -1.000 & 0.000 & -0.999 & 0.000 & -0.007 & 0.030 & 0.011 & 0.400 \\
\hline 4 & -1.000 & 0.000 & -0.998 & 0.000 & -0.001 & 0.950 & 0.014 & 0.000 \\
\hline 5 & -1.000 & 0.000 & -0.953 & 0.000 & 0.005 & 0.010 & 0.015 & 0.170 \\
\hline 6 & -1.000 & 0.000 & -0.962 & 0.000 & 0.008 & 0.000 & 0.015 & 0.040 \\
\hline 7 & -1.000 & 0.000 & -0.956 & 0.000 & 0.005 & 0.240 & 0.015 & 0.240 \\
\hline 8 & -0.998 & 0.010 & -0.907 & 0.040 & 0.005 & 0.060 & 0.014 & 0.260 \\
\hline 9 & -0.987 & 0.130 & -0.773 & 0.090 & 0.006 & 0.000 & 0.014 & 0.040 \\
\hline 10 & -0.978 & 0.020 & -0.608 & 0.230 & 0.006 & 0.000 & 0.013 & 0.000 \\
\hline \multirow[t]{2}{*}{11} & -0.951 & 0.370 & -0.587 & 0.200 & 0.006 & 0.000 & 0.010 & 0.070 \\
\hline & \multicolumn{4}{|c|}{$\begin{array}{l}\text { Panel C: Sellers' Price } \\
\text { Conditional on Survival }\end{array}$} & \multicolumn{4}{|c|}{$\begin{array}{l}\text { Panel D: \#Unique Active Listings } \\
\text { Panel D: per Seller }\end{array}$} \\
\hline 1 & -0.230 & 0.160 & -0.097 & 0.040 & -1.000 & 0.000 & -1.000 & 0.000 \\
\hline 2 & -0.247 & 0.020 & -0.019 & 0.000 & -1.000 & 0.000 & -1.000 & 0.000 \\
\hline 3 & -0.109 & 0.270 & 0.034 & 0.980 & -1.000 & 0.000 & -0.950 & 0.000 \\
\hline 4 & -0.248 & 0.000 & -0.089 & 0.000 & -1.000 & 0.000 & -0.972 & 0.000 \\
\hline 5 & -0.105 & 0.040 & 0.076 & 0.960 & -1.000 & 0.000 & -0.531 & 0.040 \\
\hline 6 & -0.087 & 0.380 & 0.668 & 0.010 & -1.000 & 0.000 & -0.406 & 0.080 \\
\hline 7 & -0.147 & 0.020 & 0.174 & 0.790 & -1.000 & 0.000 & -0.533 & 0.000 \\
\hline 8 & -0.054 & 0.730 & 0.456 & 0.000 & -0.941 & 0.190 & -0.162 & 0.800 \\
\hline 9 & -0.145 & 0.140 & 0.320 & 0.000 & -0.806 & 0.590 & 0.373 & 0.000 \\
\hline 10 & -0.137 & 0.390 & 0.146 & 0.780 & -0.689 & 0.330 & 0.717 & 0.010 \\
\hline 11 & -0.217 & 0.590 & 0.075 & 0.900 & -0.084 & 1.000 & 1.313 & 0.000 \\
\hline
\end{tabular}

Notes: This table presents the median and 75th percentile of the effect of mandatory licensing, and their one-sided p-values for sellers in different groups of pre-FSL reputation. Pre-FSL reputation is computed as the monthly average of seller reputation during the no-regulation period, taking into account sellers' inactive months, where the missing seller reputation is imputed with the seller's latest reputation up to that month. Sellers are then classified in 11 groups according to seller's pre-FSL reputation based on Alibaba's classification for stars, crowns, and diamonds. The p-value is calculated by bootstrapping. 


\section{$6.2 \quad$ Figures}

Figure 1: Hazard Ratio of NANA Food Sellers Displaying an FSL License

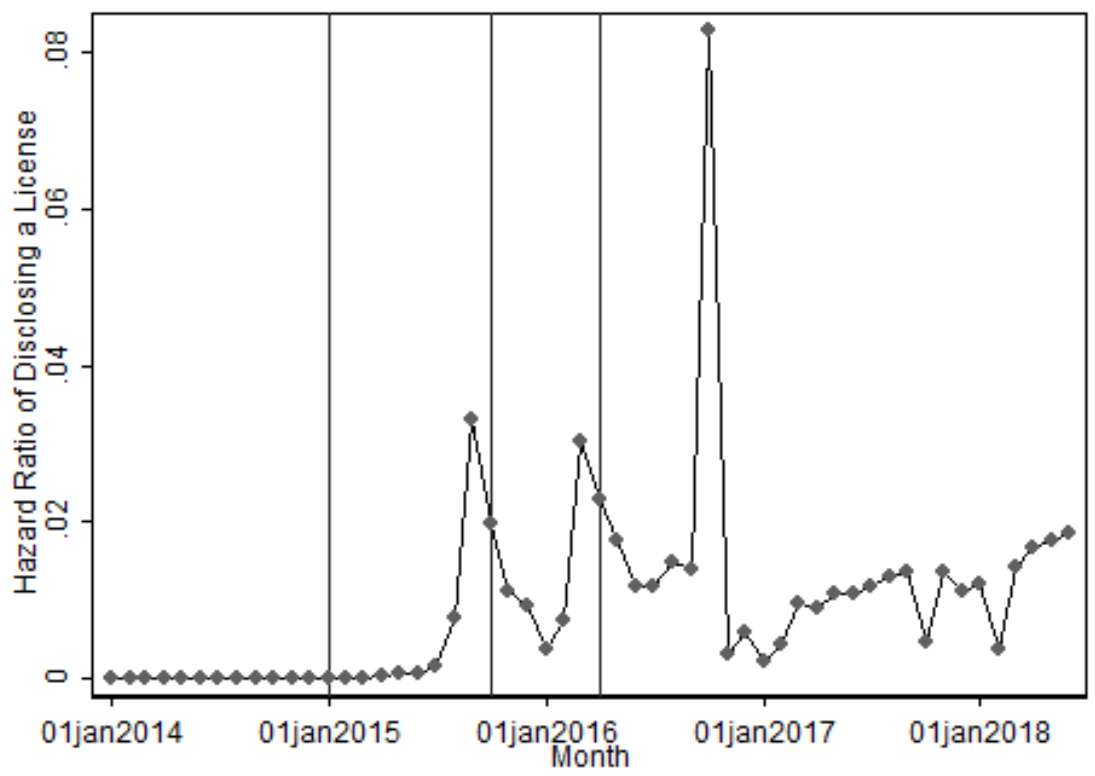

Notes: This figure presents the hazard rate of NANA food sellers displaying an FSL license in period $t$ conditional on surviving and not-licensed yet at the beginning of period $t$. The three lines are the start time of voluntary certification, partial licensing, and mandatory licensing, respectively. 
Figure 2: Hazard Ratio of NANA Food Sellers Exiting the Market

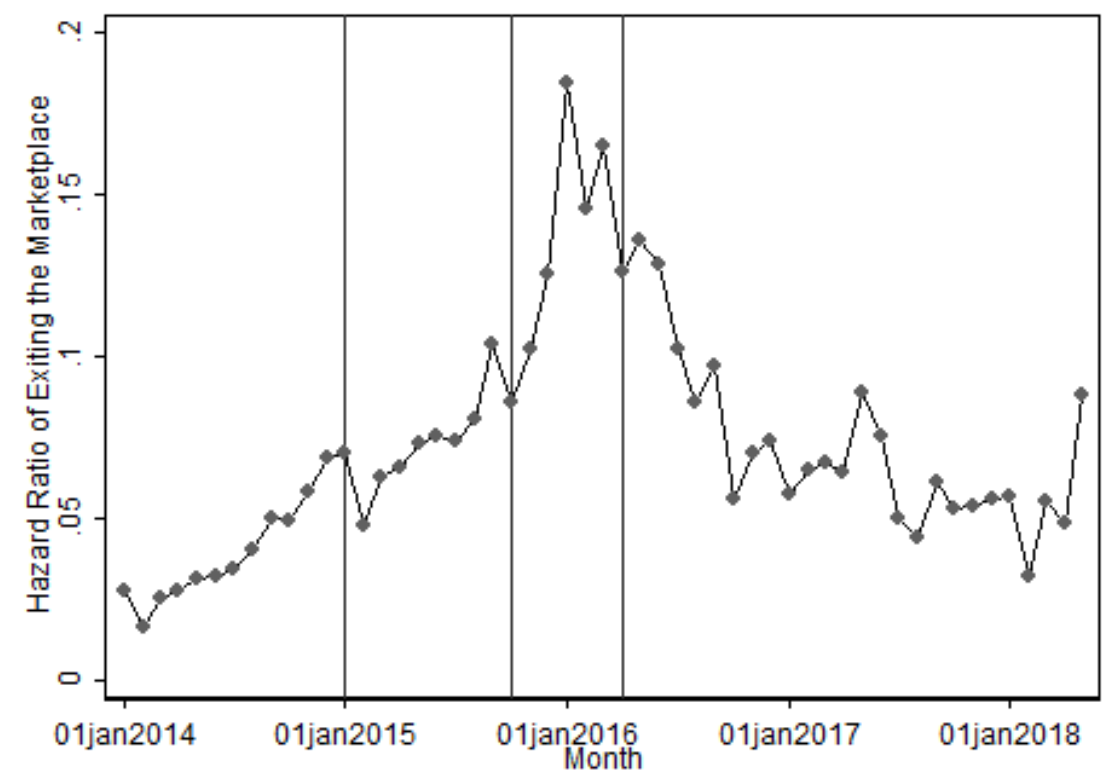

Notes: This figure presents the hazard rate of NANA food sellers exiting the market at the end of period $t$ conditional on surviving at the beginning of period $t$. The three lines are the start time of voluntary disclosing, partial licensing, and mandatory licensing, respectively. A seller is defined as exiting the market at $t$ if $t$ is the last month we observe her positive sales in NANA food and $t$ is the not the last month of our data (June 2018). 
Figure 3: Synthetic Control: Treatment Effects of the FSL on NANA Food

(a) Log of Total Number of Unique Active Sellers
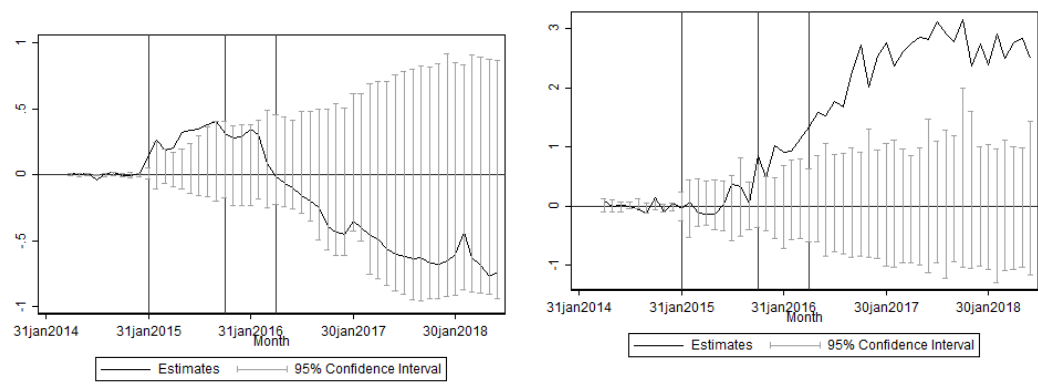

(d) Log of (1+Avg. \%Returns (e) Log of (1+Avg. \%Returns due to Quality Problem per Ac- due to Counterfeits per Active tive Seller)
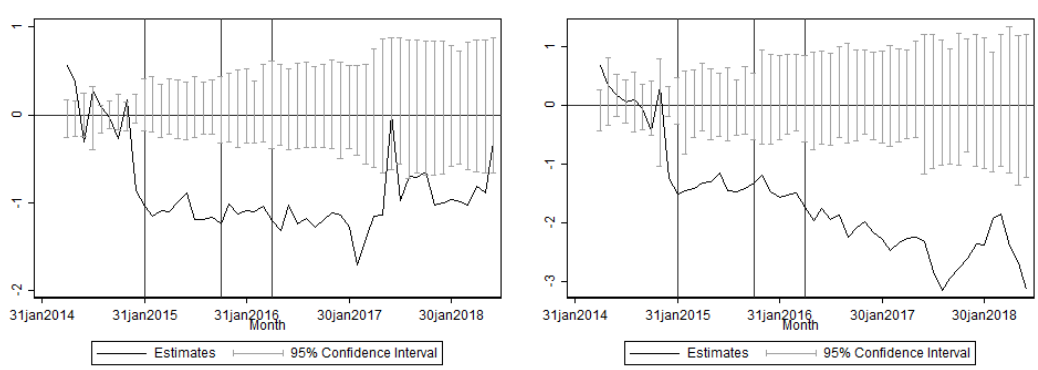

(g) Log of Total GMV

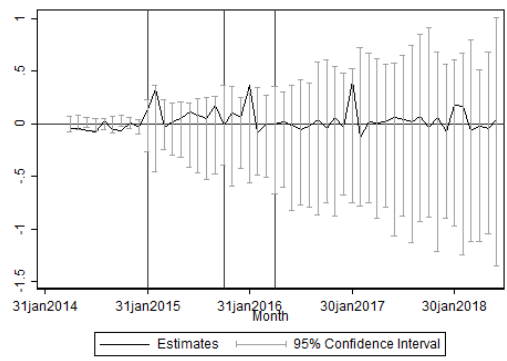

(c) Log of Avg. Rating Score per Active Seller

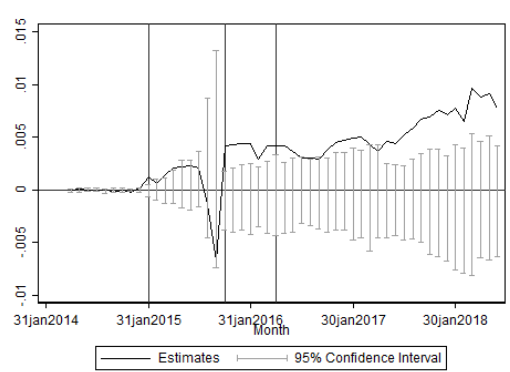

(f) Log of Avg. Price per Active Listing

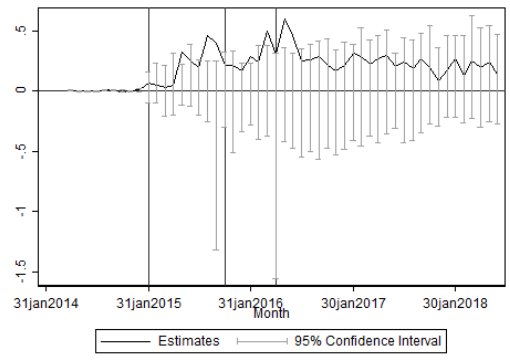

Notes: This figure shows the treatment effects of the FSL on the NANA food category. To avoid revealing Alibaba's business secrets, we only display the difference between the treated category and the synthetic control unit rather than their actual trends. The three vertical red lines are the beginning of voluntary disclosing, partial licensing, and mandatory licensing. 
Figure 4: Synthetic Control: Heterogenous Effects of the FSL by NANA Food Sellers' PreFSL GMV

(a) Sellers' GMV

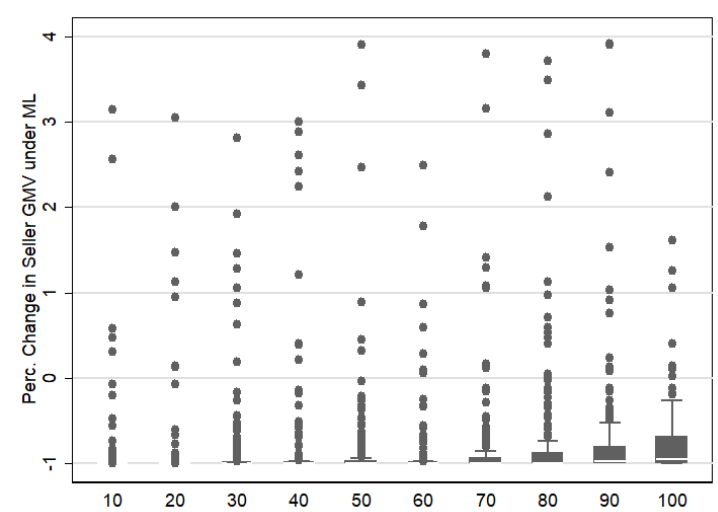

(c) Sellers' Prices Conditional on Survival

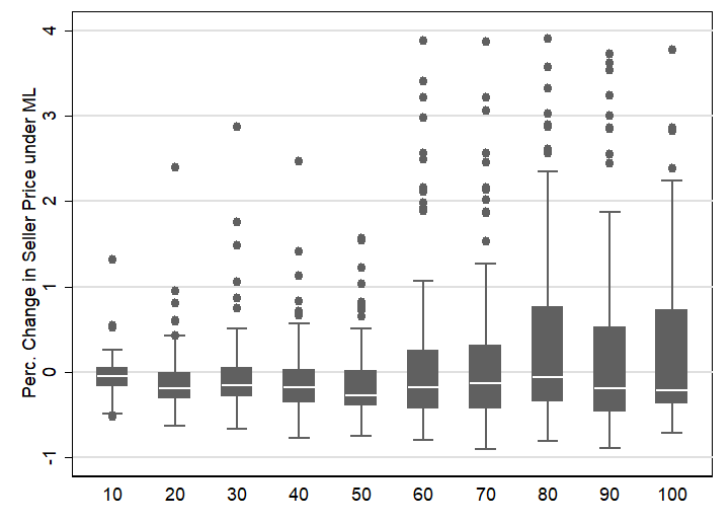

(b) Sellers' Rating Score

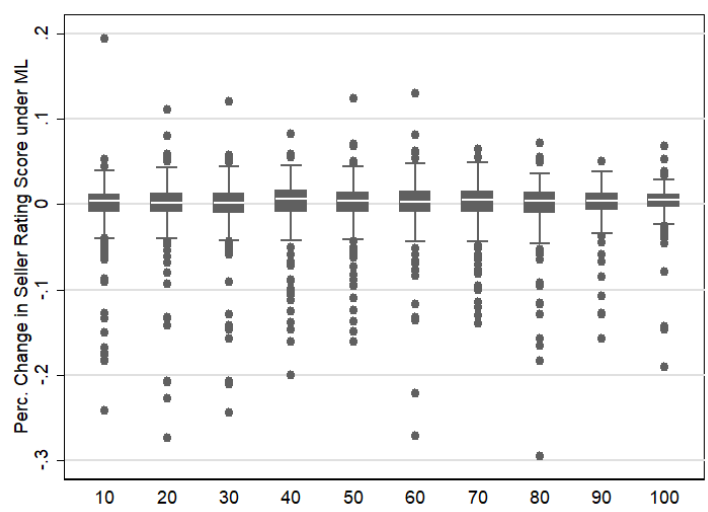

(d) \#Unique Active Listings per Seller

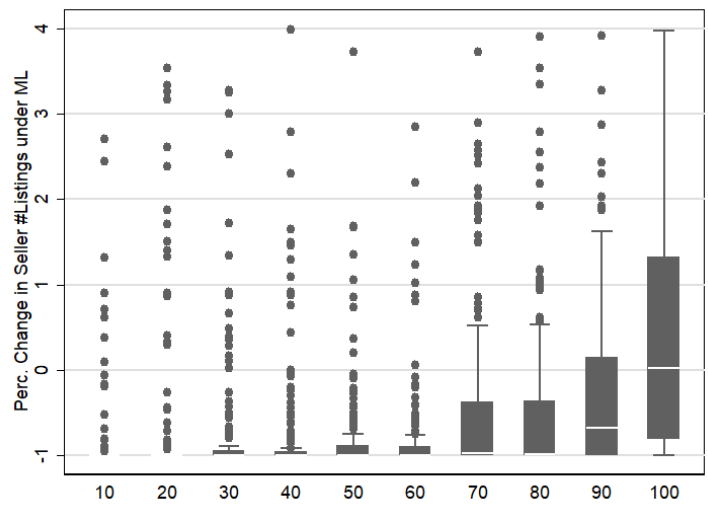

Notes: This figure displays the distribution of treatment effects of mandatory licensing on NANA food sellers by different bins of pre-FSL GMV. Using a random sample of 1,926 NANA food sellers and 5,721 individual sellers in the household categories, we estimate the treatment effect of the FSL for each NANA food seller with synthetic control. We match the pre-FSL monthly trend for the outcome variables of GMV, quality, and number of listings, and match the quarterly trend for average sales price due to missing values in inactive months. We then evenly divide NANA food sellers into 10 groups according to their pre-FSL GMV. The pre-FSL GMV is computed as the monthly average during the no-regulation period, taking into account sellers' inactive months, where a seller's missing GMV is imputed with zero. Each box indicates the 25\%, $50 \%$, and $75 \%$ percentiles of the treatment effects for a group. The upper and lower caps indicate the range of mild outliers, while the dots indicate extreme outliers. Mild and extreme outliers are defined according to the upper and lower adjacent values, which are the $25 \% / 75 \%$ percentile plus/minus 1.5 times the difference between the $75 \%$ and $25 \%$ percentiles. 
Figure 5: Synthetic Control: Heterogenous Effects of the FSL by NANA Food Sellers' preFSL Reputation

(a) Sellers' GMV

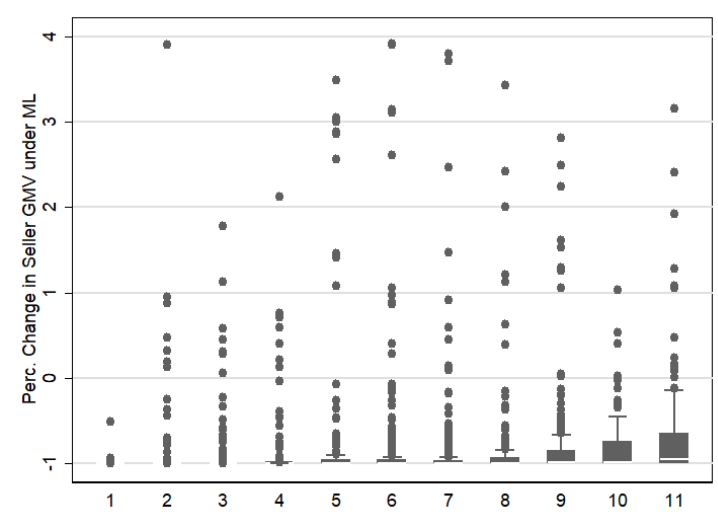

(c) Sellers' Prices

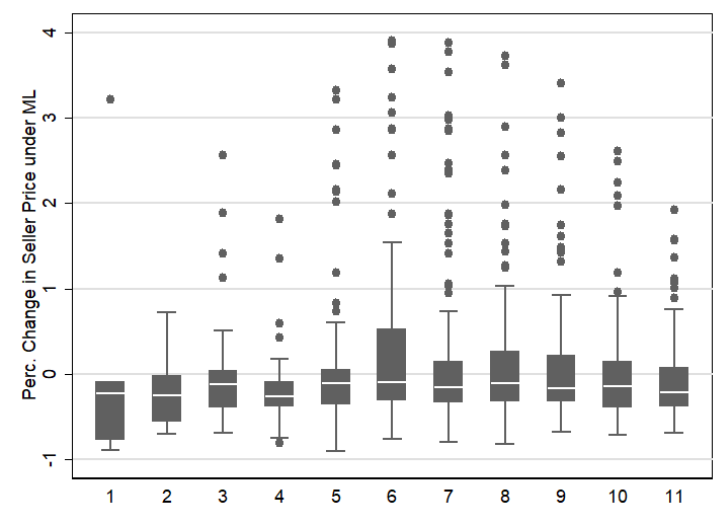

(b) Sellers' Rating Score

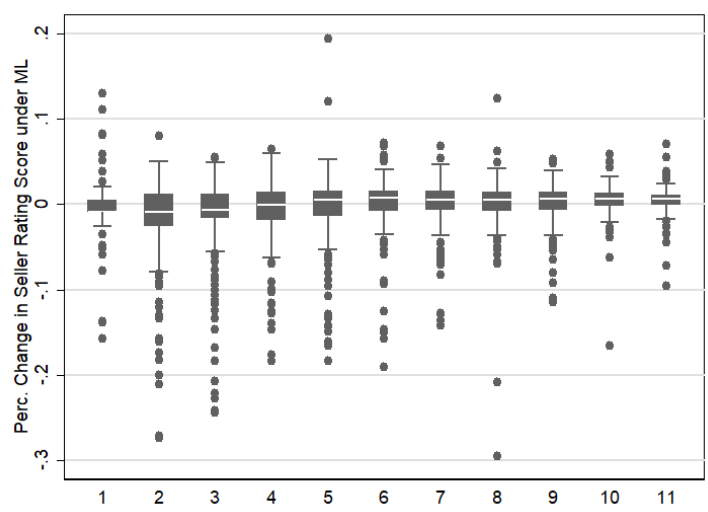

(d) \#Unique Active Listings per Seller

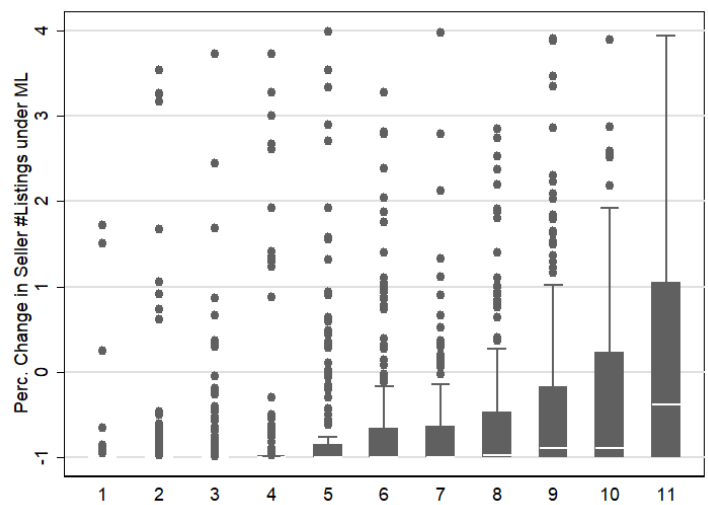

Notes: This figure displays the distribution of treatment effects of mandatory licensing on NANA food sellers in different bins of pre-FSL reputation. Using a random sample of 1,926 NANA food sellers and 5,721 individual sellers in the household categories, we estimate the treatment effect of the FSL for each NANA food seller with synthetic control. We match the pre-FSL monthly trend for the outcome variables of GMV, quality, and number of listings, and match the quarterly trend for average sales price due to missing values in inactive months. We then divide food sellers into 11 groups according to sellers' pre-FSL reputation based on Alibaba's classification of stars, crowns, and diamonds. Pre-FSL reputation is computed as the monthly average of seller reputation during the no-regulation period, taking into account sellers' inactive months, where the missing seller reputation is imputed with the seller's latest reputation up to that month. Each box shows the $25 \%, 50 \%$, and $75 \%$ percentiles of the treatment effects for a group. The upper and lower caps indicate the range of mild outliers, and the dots indicate extreme outliers. Mild and extreme outliers are defined according to the upper and lower adjacent values, which are the $25 \% / 75 \%$ percentile plus/minus 1.5 times the difference between the $75 \%$ and $25 \%$ percentiles. 
Figure 6: New Sellers: NANA Food Category vs. Household Category

(a) Pecentage of New Sellers to All Sellers

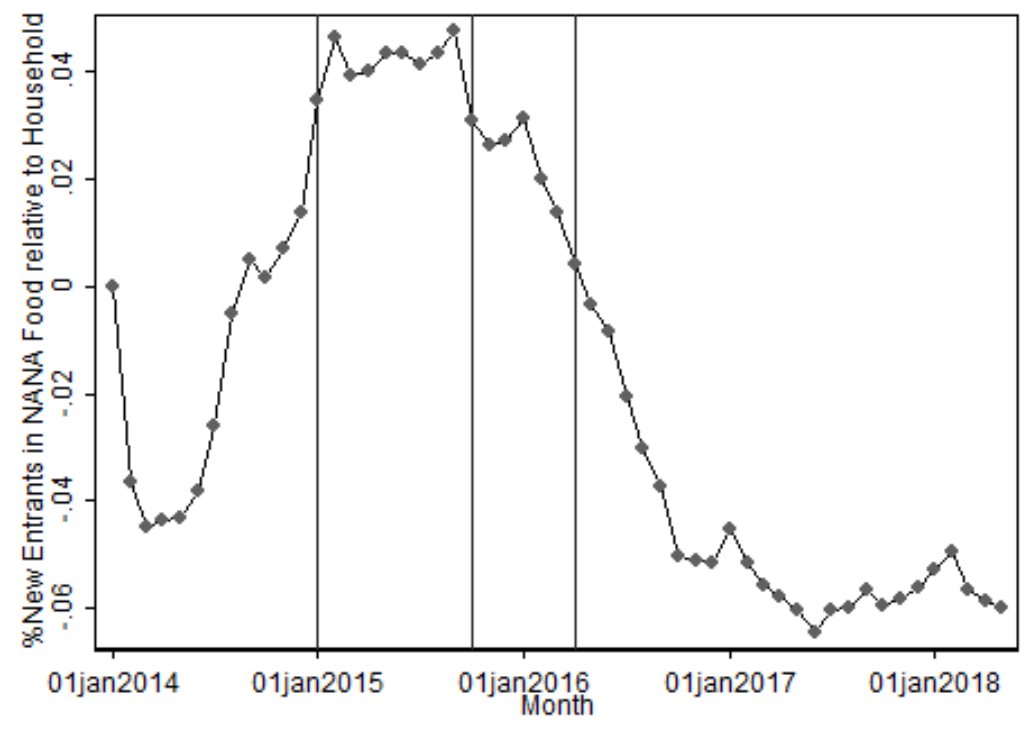

(b) New Sellers' Average Rating Score 3 months post entry

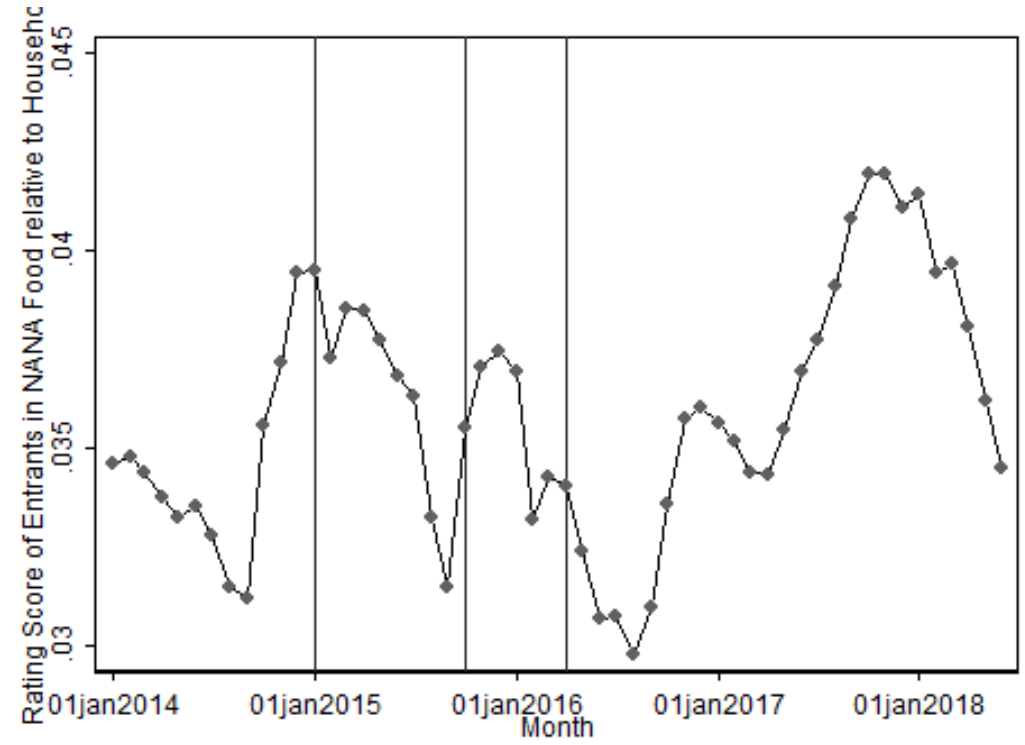

Notes: The upper figure shows the difference in percent of new sellers to all sellers between NANA food and household categories. The lower figure shows the difference in new sellers' average rating score three months post entry between the NANA food and household categories. The three straight lines indicate the start of voluntary certification, partial licensing, and mandatory licensing. A new seller is counted new in month $t$ if she first shows up in the data after January 2014 and still has sales in or after month $t$. By this definition, the new seller count is cumulative since January 2014, conditional on survival at the study time. 